\begin{tabular}{|c|l|}
\hline Title & A symmetric Cyanation with the Chiral Ru-Li Combined Catalysts \\
\hline Author(s) & Ohkuma, Takeshi; Kurono, Nobuhito \\
\hline Citation & $\begin{array}{l}\text { Synlett, 23(13), 1865-1881 } \\
\text { https://doi.org/10.1055/s0032-1316545 }\end{array}$ \\
\hline Issue Date & 2012-08 \\
\hline Doc URL & http://hdl.handle.net/2115/53010 \\
\hline Rights & ○ 2012 Georg Thieme Verlag \\
\hline Type & article (author version) \\
\hline File Information & Syn23-13_1865-1881.pdf \\
\hline
\end{tabular}

Instructions for use 


\title{
Asymmetric Cyanation with the Chiral Ru-Li Combined Catalysts
}

\author{
Takeshi Ohkuma,* Nobuhito Kurono \\ Division of Chemical Process Engineering, Faculty of Engineering, Hokkaido University, Sapporo, Hokkaido 060-8628, Japan \\ Fax+81(11)7066598; E-mail: ohkuma@eng.hokudai.ac.jp
}

\begin{abstract}
The combined systems of phenylglycinate/BINAP/Ru(II) complex and $\mathrm{Li}$ compounds have been found to act as highly reactive and enantioselective catalysts for cyanosilylation and hydrocyanation of aldehydes, $\alpha$-keto esters, $\alpha, \beta$-unsaturated ketones, and $N$-protected aldimines. In this account, we describe the concept of catalyst design, the catalytic efficiency of the novel combined systems in the asymmetric cyanation, and the proposed reaction pathway based on the spectral analysis data.

1 Introduction

2 Cyanosilylation of Aldehydes and Ketones Catalyzed by $\mathrm{LiCl}$

3 Asymmetric Cyanosilylation of Aldehydes and $\alpha$-Keto Esters

3.1 Design of Chiral $\mathrm{Ru}-\mathrm{Li}$ Combined Catalyst Systems

3.2 Cyanosilylation of Aldehydes

3.3 Cyanosilylation of $\alpha$-Keto Esters

4 Asymmetric Hydrocyanation of Aldehydes, $\alpha, \beta$ Unsaturated Ketones, and Aldimines

4.1 Hydrocyanation of Aldehydes

4.2 Conjugate Cyanation of $\alpha, \beta$-Unsaturated Ketones

4.3 Strecker-type Reaction

5 Mechanistic Considerations for Cyanosilylation of Aldehydes and Ketones

5.1 Achiral Reaction Catalyzed by $\mathrm{LiCl}$

5.2 Asymmetric Reaction with the Chiral $\mathrm{Ru}-\mathrm{Li}$ Combined Catalyst

6 Conclusion
\end{abstract}

Key words: aldehydes, asymmetric catalysis, cyanosilylation, hydrocyanation, imines, lithium, ruthenium, $\alpha, \beta$-unsaturated ketones

\section{$1 \quad$ Introduction}

Enantioselective nucleophilic cyanation of prochiral unsaturated compounds affording the optically active nitrile products is among the most useful and versatile methods in the area of synthetic organic chemistry. ${ }^{1}$ As shown in Scheme 1, aldehydes, ketones, alkenes activated by an electron-withdrawing group (EWG), and imines are cyanated with high enantioselectivity under appropriate conditions. Many bioactive chiral compounds, including $\alpha$-hydroxy carboxylic acids, $\beta$ amino alcohols, and $\alpha$-amino acids, are readily prepared from these cyanated compounds. ${ }^{1}$ The cyanation reagents can be selected according to one's synthetic purpose. For example, the cyanation with TMSCN (cyanosilylation) provides silyl-protected compounds, which are sometimes suitable for further transformations. The use of the simplest cyanation reagent $\mathrm{HCN}$ (hydrocyanation), affording unprotected chiral nitriles, is appropriate for the practical synthesis. ${ }^{2}$

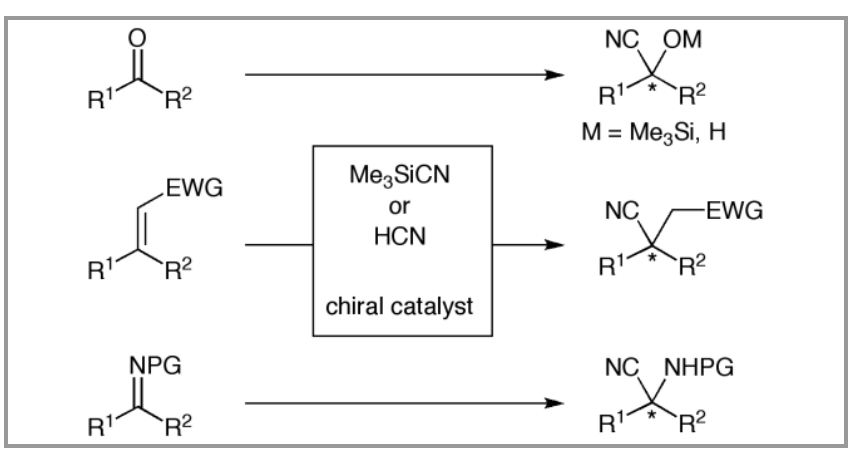

Scheme 1 Enantioselective nucleophilic cyanation with chiral catalyst by using TMSCN or HCN

Various chiral organometallic catalysts and organocatalysts have been developed for these important transformations. ${ }^{1}$ Three major indices for judgment of the catalyst efficiency are as follows: 1) catalytic activity (reflecting the amount of catalyst loading), 2) enantioselective ability, and 3) range of application for substrates. Regarding the first item, the substrate-to-catalyst molar ratio $(\mathrm{S} / \mathrm{C})$ and turnover number (TON) of the catalyst are generally used as indicators. Regarding the second item, the ability is estimated by the degree of enantiomeric excess (ee) of the cyanated products. Several welldesigned chiral catalysts have achieved very high ee of $>95 \%$ in recent years. Finally, in the case of the third index, the catalyst with wider application ability is obviously preferable.

This account describes our studies on the asymmetric cyanosilylation and hydrocyanation of aldehydes, $\alpha$ keto esters, $\alpha, \beta$-unsaturated ketones, and $N$-protected aldimines catalyzed by unique chiral $\mathrm{Ru}$ (II) complexLi compound combined systems for achieving high catalytic activity, enantioselectivity, and a wide range of substrates.

\section{Cyanosilylation of Aldehydes and Ketones Catalyzed by LiCl}

We first focused our attention on finding a catalyst that exhibits high activity in the cyanosilylation of aldehydes. When we started this research, many catalyst systems for this reaction were already known. ${ }^{1}$ Among them, Lewis acids mainly activate aldehydes by the reversible coordination at the carbonyl oxygen of the substrates. ${ }^{3}$ Lewis basic catalysts interact with the silicon moiety of TMSCN, thereby improving the nucleophilicity of 
Table 1 Cyanosilylation of Benzaldehyde (1)

\begin{tabular}{|c|c|c|c|c|c|}
\hline & - $\mathrm{H}$ & $\mathrm{Me}_{3} \mathrm{SiCN}$ & cat & & $\mathrm{X}^{\mathrm{O}}$ \\
\hline Entry & Catalyst & Method $^{b}$ & $\mathrm{~S} / \mathrm{C}^{\mathrm{c}}$ & Solvent $^{\mathrm{d}}$ & $\begin{array}{l}\text { Yield }^{\mathrm{e}} \\
(\%)\end{array}$ \\
\hline 1 & $\mathrm{LiCl}$ & $\mathrm{A}$ & 10,000 & neat & 100 \\
\hline 2 & $\mathrm{LiCl}$ & B & 10,000 & neat & 100 \\
\hline 3 & $\mathrm{LiCl}$ & A & 50,000 & neat & 56 \\
\hline 4 & $\mathrm{LiCl}$ & A & 50,000 & $\mathrm{CH}_{2} \mathrm{Cl}_{2}{ }^{\mathrm{f}}$ & $<0.3$ \\
\hline 5 & $\mathrm{LiCl}$ & $\mathrm{A}$ & 50,000 & $\mathrm{THF}^{\mathrm{f}}$ & 7 \\
\hline 6 & $\mathrm{LiCl}$ & A & 10,000 & toluene $^{\mathrm{f}}$ & 7 \\
\hline 7 & $\mathrm{NaCl}$ & B & 20 & neat & 1 \\
\hline 8 & $\mathrm{KCl}$ & B & 20 & neat & 0.3 \\
\hline 9 & $\mathrm{CsCl}$ & B & 20 & neat & 22 \\
\hline 10 & $\mathrm{LiF}$ & A & 10,000 & neat & $<0.3$ \\
\hline 11 & $\mathrm{LiBr}$ & A & 10,000 & neat & 86 \\
\hline 12 & LiI & A & 10,000 & neat & 98 \\
\hline 13 & $\mathrm{LiClO}_{4}$ & A & 10,000 & neat & 2.5 \\
\hline 14 & $\_^{\mathrm{g}}$ & - & - & neat & $<0.3$ \\
\hline \multicolumn{6}{|c|}{$\begin{array}{l}\text { a Unless otherwise described, reactions were carried out using 1a } \\
\text { and } 1 \text { equiv of TMSCN with catalyst at } 20-25^{\circ} \mathrm{C} \text { for } 1 \mathrm{~h} \text {. } \\
\text { b A: Catalyst was added as a } 29.5 \mathrm{mM} \text { solution of THF. B: } \\
\text { Catalyst was added as a solid. } \\
{ }^{\mathrm{c}} \text { Substrate/catalyst molar ratio. } \\
{ }^{\mathrm{d}} \text { Neat: The reaction was conducted under solvent-free conditions. } \\
\text { e } \text { Determined by GC or }{ }^{1} \mathrm{H} \text { NMR analysis. } \\
\text { f } \text { The initial concentration of } 1 \mathrm{a} \text { was } 1.0 \mathrm{M} \text {. } \\
{ }^{\mathrm{g}} \text { Reaction without catalyst. }\end{array}$} \\
\hline
\end{tabular}

this reagent. ${ }^{4}$ The Lewis acid-Lewis base bifunctional catalysts activate both the substrate and the reagent cooperatively. ${ }^{1 \mathrm{f}, \mathrm{i}}$ Metal halides, such as $\mathrm{AlCl}_{3},{ }^{36,4 \mathrm{a}} \mathrm{BiBr}_{3},{ }^{31} \mathrm{BF}_{3},{ }^{3 \mathrm{f}} \mathrm{InX} \mathrm{X}_{3}\left(\mathrm{X}=\mathrm{Br}^{3 \mathrm{o}} \mathrm{F}^{3 \mathrm{~m}}\right), \mathrm{LnCl}_{3}$ $(\mathrm{Ln}=\mathrm{La}, \mathrm{Ce}, \mathrm{Sm}),{ }^{3 \mathrm{e}} \mathrm{MgBr}_{2},{ }^{3 \mathrm{f}} \mathrm{SnCl}_{4},{ }^{3 \mathrm{f}} \mathrm{R}_{2} \mathrm{SnCl}_{2}(\mathrm{R}=$ $\left.n-\mathrm{C}_{4} \mathrm{H}_{9}, \mathrm{C}_{6} \mathrm{H}_{5}\right),{ }^{3 \mathrm{j}}{ }^{\mathrm{TiCl}}{ }_{4},{ }^{3 \mathrm{f}}$ and $\mathrm{ZnI}_{2},{ }^{3 \mathrm{a}}$ have been reported as typical Lewis acidic catalysts. However, the catalytic behavior of $\mathrm{LiCl}$, which is one of the simplest metal halides, has not been investigated for this reaction. ${ }^{5}$ Thus, we decided to examine the catalytic efficiency of $\mathrm{LiCl}$ in the cyanosilylation of aldehydes in detail.

Benzaldehyde (1a), an aromatic aldehyde, was selected as the standard substrate. As shown in Table 1, LiCl showed significantly high catalytic activity under solvent-free conditions at ambient temperature. ${ }^{6}$ The aldehyde 1a was quantitatively converted with 1 equiv of TMSCN at an S/C of 10,000 in $1 \mathrm{~h}$ to afford the silylated cyanohydrin $\mathbf{2 a}$ (entries 1 and 2). $\mathrm{LiCl}$ could be used as either a solid or a THF solution. The reaction with an $\mathrm{S} / \mathrm{C}$ of 50,000 proceeded to $56 \%$ even in $1 \mathrm{~h}$ (entry 3 ). Interestingly, the reaction rate notably decreased in solution $\left([\mathbf{1} \mathbf{a}]_{0}=1.0 \mathrm{M}\right)$ (entries 4-6). Other alkaline metal chlorides, $\mathrm{NaCl}, \mathrm{KCl}$, and $\mathrm{CsCl}$, as well as $\mathrm{LiF}$ were far less active under the same conditions (entries 7-10). 7,8 The catalytic efficiency of $\mathrm{LiBr}$ and LiI was comparable (entries 11 and 12). $\mathrm{LiClO}_{4}$, which has been reported to promote the cyanation of aldehydes and ketones, ${ }^{9}$ did not exhibit sufficient catalytic activity under the regular conditions (entry 13). These results indicated that exceptionally high reactivity is achieved by using LiX $(\mathrm{X}=\mathrm{Cl}, \mathrm{Br}, \mathrm{I})$ as a catalyst under solvent-free conditions.

The cyanosilylation catalyzed by $\mathrm{LiCl}$ was applied to a range of aldehydes 1 (Table 2). ${ }^{6}$ The cyanated products, $\mathbf{2}$ and 3, were isolated with $>98 \%$ purity just by distillation of the reaction mixture. The reaction of 1a and TMSCN with an S/C of 100,000 for $48 \mathrm{~h}$ afforded $\mathbf{2 a}$ in $99 \%$ yield (entry 2 ). A bulky reagent $t$ $\mathrm{BuMe}_{2} \mathrm{SiCN}$ could be used with a slightly lower reaction rate (entries 3, 6, 12, and 17). The benzaldehydes with an electron-donating group (EDG) at the $\mathrm{C} 4$ position, $\mathbf{1 b}$ and $\mathbf{1 e}$, showed relatively low reactivity (entries 4 and 8 ). On the other hand, the reaction of the electron-withdrawing $\mathrm{Cl}$ - or $\mathrm{CF}_{3}$-substituted aldehydes at the $\mathrm{C} 2$ or $\mathrm{C} 4$ position, 1c, 1d, and 1f, with an S/C of 10,000 was completed within $40 \mathrm{~min}$ (entries 5, 7, and 9). 2Naphthaldehyde (1g) also showed high reactivity (entry 10). The cyanation of $\alpha, \beta$-unsaturated aldehydes, $\mathbf{1 h}$ and $\mathbf{1 i}$, proceeded in a 1,2-fashion (entries 11-13). Formation of the 1,4-cyanated products was not observed at all. The reactivity of

Table 2 Cyanosilylation of Aldehydes 1 Catalyzed by $\mathrm{LiCl}^{\mathrm{a}}$

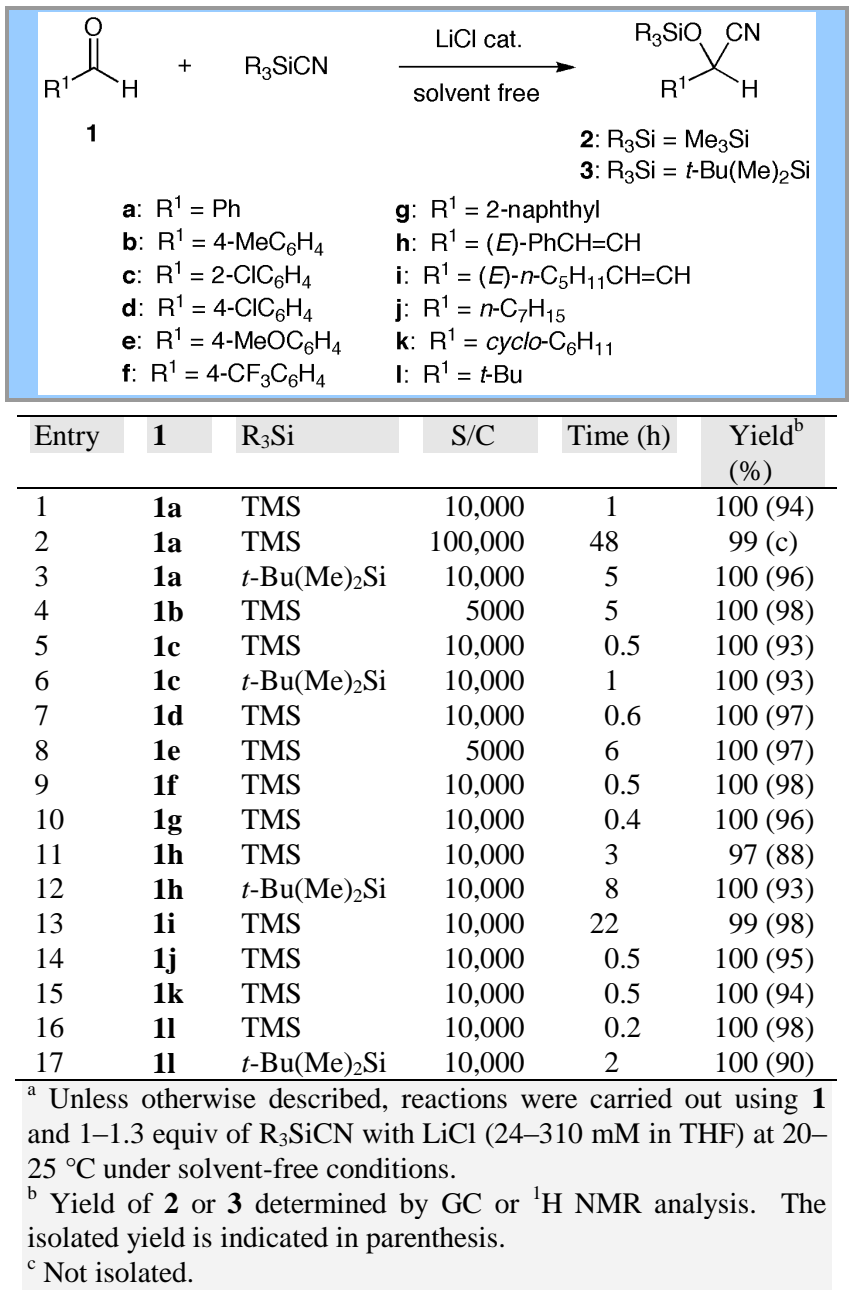


aliphatic aldehydes, $\mathbf{1 j} \mathbf{j} \mathbf{1 1}$, was found to be notably high (entries 14-17). The bulky aldehyde 1I quantitatively reacted with TMSCN in only $10 \mathrm{~min}$ under the typical conditions.

We next examined the cyanosilylation of ketones 4 catalyzed by $\mathrm{LiCl}$. These results are listed in Table 3. ${ }^{6,10}$ As we expected, the reactivity of acetophenone (4a), a simple aromatic ketone, was found to be much lower than that of aromatic aldehyde 1a (entry 1 and Table 2, entry 1). The reaction with an S/C of 100 was completed in $3 \mathrm{~h}$. Although the 2'- and 4'chloroacetophenones, $\mathbf{4 b}$ and $\mathbf{4 c}$, showed the same level of reactivity, the 4'-bromo ketone $4 \mathbf{d}(\mathrm{S} / \mathrm{C}=$ 1000) was quantitatively converted into the cyanohydrin derivative 5d in $6 \mathrm{~h}$ (entries 2-4). Furthermore, acetophenones with strong EWGs of $\mathrm{CF}_{3}(\mathbf{4 e}), \mathrm{CN}(\mathbf{4 f})$, and $\mathrm{NO}_{2}(\mathbf{4 g})$ exhibited even higher reactivity (entries 5-7). The reactivity of methoxyacetophenones, $\mathbf{4 h}$ and $\mathbf{4 i}$, was low, but the cyanation with an S/C of 100 was completed within 8 h (entries 8 and 9). Acetylpyridines, $\mathbf{4 j}$ and $\mathbf{4 k}$, showed remarkably high reactivity (entries 10 and 11). The cyanation of 2 -acetylpyridine $(\mathbf{4 j})$ with an $\mathrm{S} / \mathrm{C}$ of 20,000 was completed in $45 \mathrm{~min}$. The reactivity of the vinylic and alphatic ketones, $4 \mathbf{l}$ and $\mathbf{4 m}$, was similar to that of the aromatic ketone $\mathbf{4 a}$ (entries 1, 12, and 13). The 1,2-adduct $5 \mathbf{I}$ was the only detectable

Table 3 Cyanosilylation of Simple Ketones 4 Catalyzed by $\mathrm{LiCl}^{\mathrm{a}}$

\begin{tabular}{|c|c|c|c|c|}
\hline \multicolumn{3}{|c|}{ 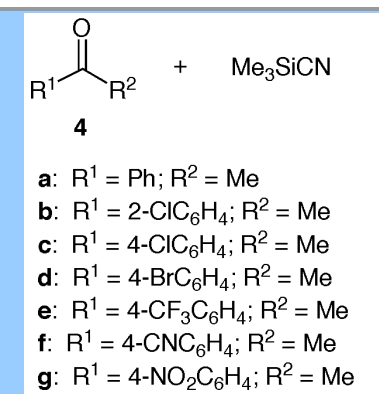 } & \multicolumn{2}{|c|}{$\begin{array}{l}\text { h: } \mathrm{R}^{1}=2-\mathrm{MeOC}_{6} \mathrm{H}_{4} ; \mathrm{R}^{2}=\mathrm{Me} \\
\mathrm{i}: \mathrm{R}^{1}=4-\mathrm{MeOC}_{6} \mathrm{H}_{4} ; \mathrm{R}^{2}=\mathrm{Me} \\
\mathrm{j}: \mathrm{R}^{1}=2-\text { pyridyl; } \mathrm{R}^{2}=\mathrm{Me} \\
\mathbf{k}: \mathrm{R}^{1}=4-\text { pyridyl; } \mathrm{R}^{2}=\mathrm{Me} \\
\text { : } \mathrm{R}^{1}=(\mathrm{E})-\mathrm{PhCH}=\mathrm{CH} ; \mathrm{R}^{2}=\mathrm{Me} \\
\mathbf{m}: \mathrm{R}^{1}=n-\mathrm{Bu} ; \mathrm{R}^{2}=n-\mathrm{Bu}\end{array}$} \\
\hline Entry & 4 & $\mathrm{~S} / \mathrm{C}$ & Time (h) & Yield $(\%)^{\mathrm{b}}$ \\
\hline 1 & $4 a$ & 100 & 3 & $100(96)$ \\
\hline 2 & $4 b$ & 100 & 2 & $99.8(97)$ \\
\hline 3 & $4 c$ & 100 & 2.5 & $99.1(98)$ \\
\hline 4 & $4 d$ & 1000 & 6 & 99.8 (97) \\
\hline 5 & $4 e$ & 1000 & 1.5 & $100(98)$ \\
\hline 6 & $4 f$ & 1000 & 1 & 100 (99) \\
\hline 7 & $4 g$ & 1000 & 1 & $100(98)$ \\
\hline 8 & $4 \mathrm{~h}$ & 100 & 5 & $99.6(96)$ \\
\hline 9 & $4 \mathbf{i}$ & 100 & 8 & 99.7 (98) \\
\hline 10 & $\mathbf{4 j}$ & $20.000^{c}$ & 0.75 & $100(80)$ \\
\hline 11 & $4 \mathbf{k}$ & 1000 & 0.5 & $99.6(96)$ \\
\hline 12 & 41 & 100 & 3 & $100(98)$ \\
\hline 13 & $4 m$ & 100 & 2.5 & $100(94)$ \\
\hline
\end{tabular}

${ }^{a}$ Unless otherwise described, reactions were carried out using 5 mmol of 4 and 1-1.3 equiv of TMSCN with $\mathrm{LiCl}(200-220 \mathrm{mM}$ in THF) at $20-25{ }^{\circ} \mathrm{C}$. The total volume of THF was $0.24-0.76 \mathrm{~mL}$ (reaction with an S/C $=100$ ), $0.52-1.03 \mathrm{~mL}$ (reaction with an S/C $=1000$ ), or $0.01 \mathrm{~mL}$ (reaction with an $\mathrm{S} / \mathrm{C}=20,000$ ).

${ }^{\mathrm{b}}$ Yield of $\mathbf{5}$ determined by GC or ${ }^{1} \mathrm{H}$ NMR analysis. The isolated yield is indicated in parenthesis.

${ }^{\mathrm{c}} 25 \mathrm{mM}$ of $\mathrm{LiCl}$ in THF was used. product in the reaction of $\mathbf{4 1}$.

We found that exceptionally high catalytic activity of $\mathrm{LiCl}$ was achieved in the reaction of $\alpha$-heterosubstituted ketones 6 and TMSCN (Table 4). ${ }^{3 \mathrm{~d}, \mathrm{n}, \mathrm{o}, 4 \mathrm{~d}, \mathrm{~g}, 11}$ Thus, the reaction of 2-methoxyacetophenone (6a) with an S/C of 5000 was completed in 30 min (entry 1). ${ }^{10} \quad$ Phenylglyoxal diethylacetal (6b) and methylglyoxal dimethylacetal (6c), which are aromatic and aliphatic $\alpha, \alpha$-dialkoxyketones, quantitatively reacted with TMSCN at an S/C of $100,000 \mathrm{in} 1 \mathrm{~h}$ and $15 \mathrm{~min}$, respectively (entries 2 and $3)$. The acceleration effect of the $\alpha$-alkoxy groups of ketones can be clearly seen by comparing the reactivity of $\mathbf{6 a}, \mathbf{b}$ and $\mathbf{4 a}$ (see Table 3 , entry 1 ). The $\alpha$-dimethylamino- and $\alpha$-chloroacetophenones, $6 \mathbf{d}$ and $\mathbf{6 e}$, were also quantitatively cyanated with a tiny amount of $\mathrm{LiCl}$ (entries 4 and 5).

Table 4 Cyanosilylation of $\alpha$-Hetero-substituted Ketones 6 Catalyzed by $\mathrm{LiCl}^{\mathrm{a}}$

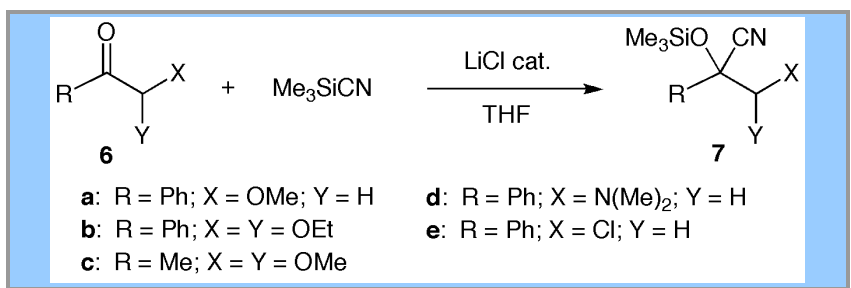

\begin{tabular}{llccc}
\hline Entry & $\mathbf{6}$ & S/C & Time $(\mathrm{h})$ & Yield $(\%)^{\mathrm{b}}$ \\
\hline 1 & $\mathbf{6 a}$ & 5000 & 0.5 & $100(97)$ \\
2 & $\mathbf{6 b}$ & 100,000 & 1 & $99.9(96)$ \\
3 & $\mathbf{6 c}$ & 100.000 & 0.25 & $100(95)$ \\
4 & $\mathbf{6 d}$ & 5000 & 3 & $100(97)$ \\
$5^{\mathrm{c}}$ & $\mathbf{6 e}$ & 10,000 & 1 & $100(98)$ \\
\hline${ }^{\mathrm{a}}$ Unless otherwise described, reactions were carried out using 5 \\
mmol of $\mathbf{6}$ and 1.3 equiv of TMSCN with LiCl at 20-25 ${ }^{\circ} \mathrm{C}$. The \\
total volume of THF was 0.01 mL. \\
${ }^{\mathrm{b}}$ Yield of $\mathbf{5}$ determined by GC or ${ }^{1} \mathrm{H} \mathrm{NMR}$ analysis. The isolated \\
yield is indicated in parenthesis. \\
${ }^{{ }^{c}}$ The total volume of THF was $0.51 \mathrm{~mL}$.
\end{tabular}

The Lewis acidic character of $\mathrm{LiCl}$ was expected to control the diastereoselectivity in the cyanosilylation of 2-alkoxypropiophenones 8 (Scheme 2). ${ }^{12}$ When the 2-benzyloxy ketone 8a $(1.0 \mathrm{mmol})$ and 1.3 equiv of TMSCN were reacted in the presence of $\mathrm{LiCl}(\mathrm{S} / \mathrm{C}=$ 5000) in $\mathrm{CH}_{2} \mathrm{Cl}_{2}(0.5 \mathrm{~mL})$ at $27^{\circ} \mathrm{C}$ for $1.5 \mathrm{~h}$, anti- and syn-9a were quantitatively obtained in a $14: 1$

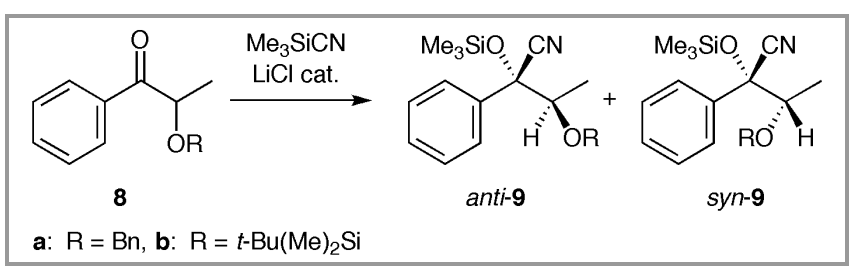

Scheme 2 Diastereoselective cyanosilylation of ketones 8 catalyzed by $\mathrm{LiCl}$ 
ratio. $^{10}$ The anti/syn ratio decreased to $6: 1$ in polar THF $(0.1 \mathrm{~mL})$ solution. These observations suggested that the cyanation proceeded through a chelation intermediate consisting of the Li cation and $8 \mathbf{a}$ (see Section 5.1 for details). ${ }^{12}$ Interestingly, the reaction of 8b with a bulky tert- $\mathrm{Bu}(\mathrm{Me})_{2} \mathrm{SiO}$ group in $\mathrm{CH}_{2} \mathrm{Cl}_{2}$ also gave anti-9b as a major isomer $($ anti/syn $=3: 1){ }^{13}$

3

\section{Asymmetric Cyanosilylation Aldehydes and $\alpha$-Keto Esters}

\subsection{Design of Chiral Ru-Li Combined Catalyst Systems}

The notably high catalytic activity of $\mathrm{LiCl}$ in the cyanosilylation of aldehydes and ketones prompted us to design chiral $\mathrm{Li}$ catalysts for development of the enantioselective reaction. Kagan ${ }^{14}$ and Ishihara ${ }^{15}$ have reported elegant asymmetric cyanosilylation of aldehydes with chiral $\mathrm{Li}$ catalysts derived from BINOL and SALEN compounds. Our concept for the design of catalysts was very much different from others. As shown in Figure 1, we expected that the Li cation could be coordinated by a chiral metal complex to form a chiral metal- $\mathrm{Li}$ combined catalyst. Metal complexes have an advantage for the formation of a variety of chiral structures from chiral ligands and the center metals with coordination bonds. Here, the metal complexes are recognized as "chiral templates," which are readily modified just by changing the chiral ligands.

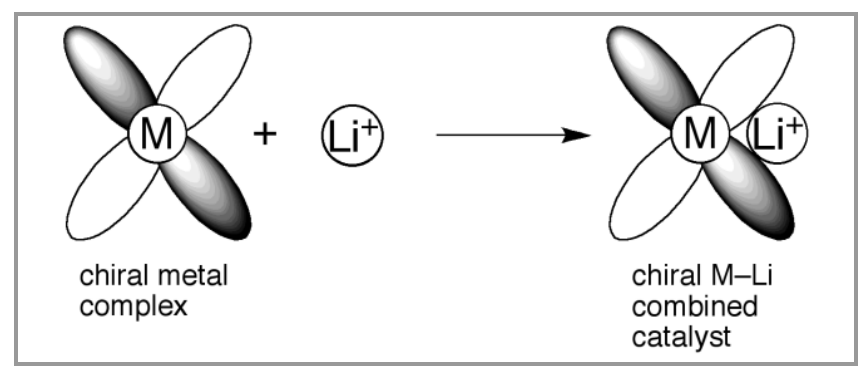

Figure 1 Working hypothesis for the design of the catalyst

Since 1995, we have studied asymmetric hydrogenation of ketones catalyzed by $\mathrm{Ru}(\mathrm{II})$ complexes bearing both chiral diphosphine and diamine ligands. ${ }^{16}$ The typical structure of the catalyst precursor is shown in the upper part of Figure 2. ${ }^{17}$ The chiral structure of the Ru(II) complex varies as the combination of these two chiral ligands is changed. A wide variety of ketones have been hydrogenated with high enantioselectivity by using appropriately tuned chiral diphosphine/diamine-Ru(II) complexes. Based on the positive results from the asymmetric hydrogenation, we planned to utilize chiral $\mathrm{Ru}(\mathrm{II})$ complexes as the chiral templates for achieving high enantioselectivity in cyanation reactions. After screening of $\mathrm{Ru}(\mathrm{II})$ complexes with two chiral ligands,

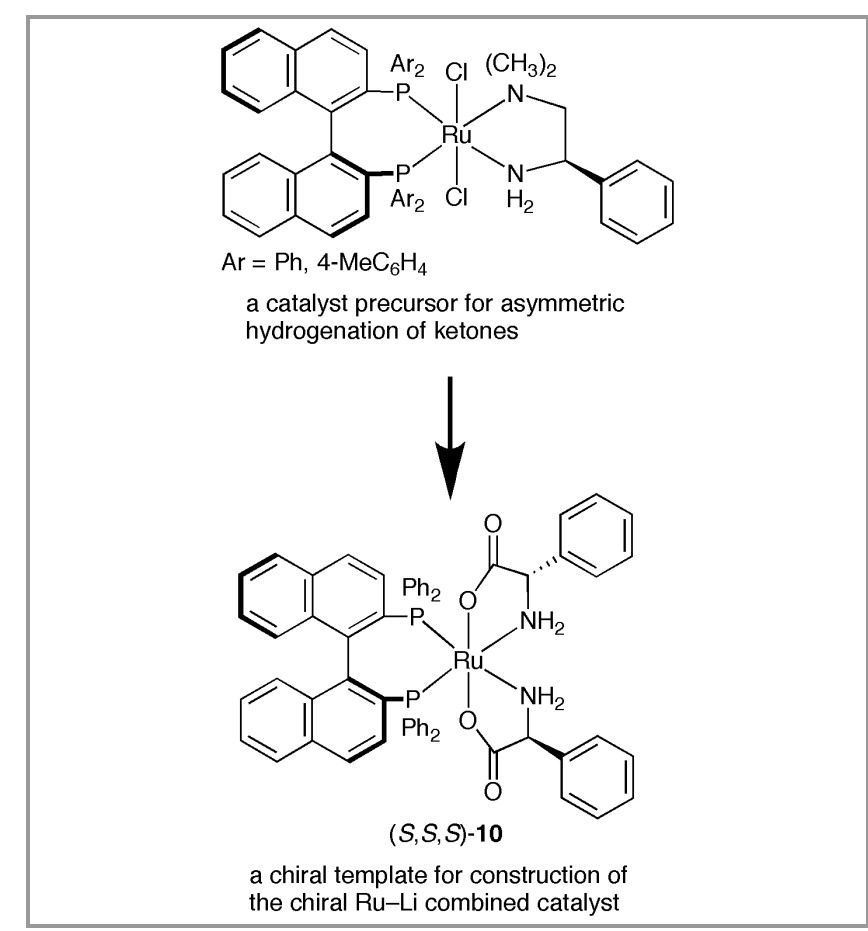

Figure 2 Design of a chiral template for construction of the chiral $\mathrm{Ru}-\mathrm{Li}$ combined catalyst

the chiral amino acid/diphosphine- $\mathrm{Ru}(\mathrm{II})$ complexes were found to have sufficient stability for use as the chiral templates. The structure of $\operatorname{Ru}[(S) \text {-phgly }]_{2}[(S)$ binap] $((S, S, S)$-10: PhGly = phenylglycinate, BINAP $=2,2^{\prime}$-bis(diphenylphosphino)-1,1'-binaphthyl) is shown as a typical example in the lower part of Figure 2. ${ }^{18,19} \mathrm{The} \mathrm{Ru}(\mathrm{II})$ complex $(S, S, S)-\mathbf{1 0}$ was readily prepared from commercial $\left[\mathrm{RuCl}_{2}\left(\eta^{6} \text {-benzene }\right)\right]_{2}$ in two steps, and purified with a silica-gel preparative TLC in the open air (74\% isolated yield: Scheme 3$)$.

\begin{tabular}{|c|c|c|}
\hline \multirow{2}{*}{$1 / 2\left[\mathrm{RuCl}_{2}\left(\eta^{6} \text {-benzene }\right)\right]_{2}$} & $\begin{array}{l}\text { 1. (S)-BINAP ( } 1 \text { equiv), } \\
\text { DMF, } 100^{\circ} \mathrm{C}, 10 \mathrm{~min}\end{array}$ & \multirow{2}{*}{$\begin{array}{l}(S, S, S)-10 \\
74 \% \text { yield }\end{array}$} \\
\hline & $\begin{array}{l}\text { 2. sodium (S)-phenylglycinate } \\
\text { ( } 3 \text { equiv) } \\
\text { DMF- } \mathrm{CH}_{3} \mathrm{OH}, 25^{\circ} \mathrm{C}, 12 \mathrm{~h}\end{array}$ & \\
\hline
\end{tabular}

Scheme 3 Preparation of $(S, S, S)-\mathbf{1 0}$

\subsection{Cyanosilylation of Aldehydes}

The reaction of benzaldehyde (1a) and a 1.2 equiv of TMSCN in tert-BuOMe was selected for screening of the amino acid/BINAP-Ru(II) complexes (Table 5). ${ }^{14,15,20}$ The catalytic species was prepared in situ from the complex and $\mathrm{LiCl}$ in a 1:1 ratio. The $\mathrm{S} / \mathrm{C}$ was set at 10,000:1. When the reaction was conducted with the $(S)$-PhGly/(S)-BINAP complex $(\mathrm{R}=\mathrm{Ph})$ at $0{ }^{\circ} \mathrm{C}$, the $R$ cyanated product $(R)-\mathbf{2 a}$ in $73 \%$ ee was quantitatively obtained in $1 \mathrm{~h}$ (entry 1$){ }^{18}$ The higher enantioselectivity was obtained at the lower reaction temperature (entries 2-4). Thus, the excellent ee value of $94 \%$ was observed at $-78^{\circ} \mathrm{C}$, but the reaction rate was significantly decreased ( $18 \%$ in $18 \mathrm{~h})$. Many 
$(S)$-arylglycinate/(S)-BINAP complexes $(\mathrm{R}=$ aryl group) were applied to this reaction (entries 5-11). The electronic and steric modifications on the aromatic moiety did not improve the enantioselectivity. The use of the 2'-anisylglycinate complex almost lost the stereoselectivity, which may have been due to the inhibitory effect of the 2'-methoxy moiety interacting appropriately with $\mathrm{LiCl}$ (entry 7). Less satisfactory results were obtained by using the $\mathrm{Ru}(\mathrm{II})$ complexes with glycinate and anions of alkyl-substituted $\alpha$ amino acids (entries 12-16). The reaction with the diastereomeric $(R)$-PhGly/(S)-BINAP complex resulted in the $(S)-\mathbf{2 a}$ in only $2 \%$ ee, indicating that the appropriate combination of stereochemistry of the two chiral ligands is crucial to obtain high enantioselectivity (entry 17; see also entry 1).

Table 5 Asymmetric Cyanosilylation of Benzaldehyde (1a) with Ru Complex-LiCl Catalyst Systems ${ }^{\mathrm{a}}$

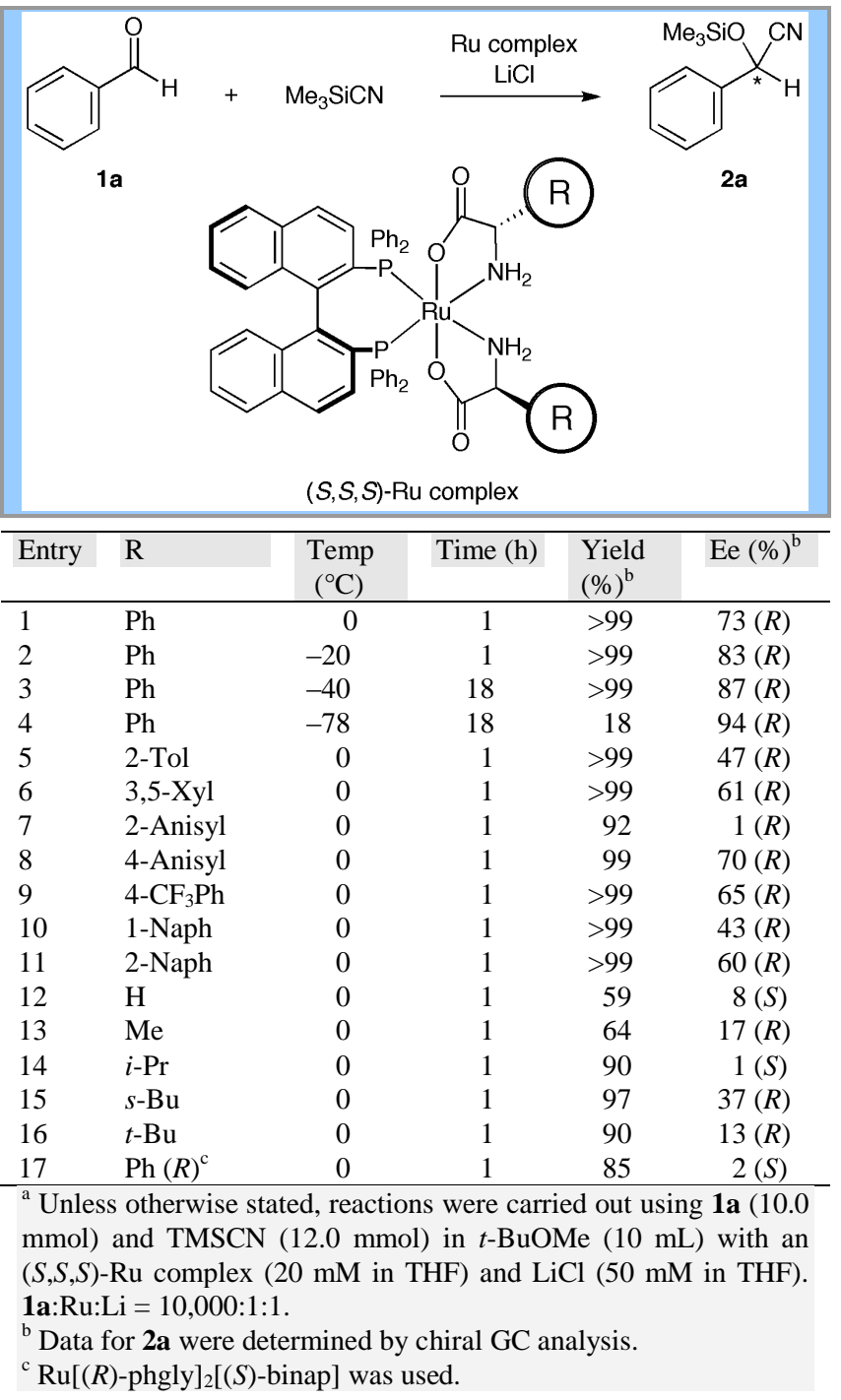

The catalytic activity of $(S, S, S)-\mathbf{1 0}-\mathrm{LiCl}$ was not sufficient for the reaction of $1 \mathrm{a}$ and TMSCN at $-78^{\circ} \mathrm{C}$, although the enantioselectivity was high (Table 5 , entry 4). We therefore used the basic salt $\mathrm{Li}_{2} \mathrm{CO}_{3}{ }^{21}$ instead of neutral $\mathrm{LiCl}$, because the $\mathrm{LiCO}_{3}$ anion was expected to strongly activate TMSCN as a nucleophile. The results are summarized in Table 6 . The cyanation of $\mathbf{1 a}$ with the $(S, S, S)-\mathbf{1 0}-\mathrm{Li}_{2} \mathrm{CO}_{3}$ catalyst system at a $\mathbf{1 a} / \mathbf{1 0} / \mathrm{Li}_{2} \mathrm{CO}_{3}$ ratio of $10,000: 1: 1$ in ether at $-78{ }^{\circ} \mathrm{C}$ was completed in $12 \mathrm{~h}$ to afford $(R)-\mathbf{2 a}$ in $97 \%$ ee (entry 1). The 1:2 10- $\mathrm{Li}_{2} \mathrm{CO}_{3}$ system showed slightly lower enantioselectivity (entry 2 ). The reaction rate slowed with decrease of the $\mathrm{Li}_{2} \mathrm{CO}_{3}$ proportion in the catalyst system (entries 3 and 4). No conversion was observed in the absence of the Li salt (entry 5). $\mathrm{Li}_{2} \mathrm{CO}_{3}$ alone exhibited moderate activity, suggesting that the complexation of $\mathbf{1 0}$ and $\mathrm{Li}_{2} \mathrm{CO}_{3}$ forms the more reactive chiral catalyst (entry 6). The enantioselectivity of the reaction in tert-BuOMe was slightly lower (entry 7). Interestingly, both the reactivity and the stereoselectivity were significantly decreased in THF (entry 8). A moderate catalyst efficiency was observed in the less polar solvents (entries 9 and 10).

Table 6 Asymmetric Cyanosilylation of Benzaldehyde (1a) ${ }^{\mathrm{a}}$

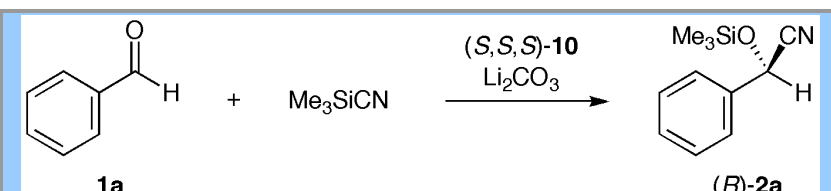

\begin{tabular}{lllcl}
\hline Entry & $\mathbf{1 a} / \mathbf{1 0} / \mathrm{Li}_{2} \mathrm{CO}_{3}$ & Solvent & Yield $(\%)^{\mathrm{b}}$ & $\mathrm{Ee} \mathrm{( \% )}$ \\
\hline 1 & $10,000: 1: 1$ & $\mathrm{Et}_{2} \mathrm{O}$ & $>99$ & 97 \\
2 & $10,000: 1: 2$ & $\mathrm{Et}_{2} \mathrm{O}$ & $>99$ & 95 \\
3 & $10,000: 1: 0.5$ & $\mathrm{Et}_{2} \mathrm{O}$ & 98 & 97 \\
4 & $10,000: 1: 0.2$ & $\mathrm{Et}_{2} \mathrm{O}$ & 9 & 98 \\
5 & $10,000: 1: 0$ & $\mathrm{Et}_{2} \mathrm{O}$ & $<1$ & n.d. $^{\mathrm{c}}$ \\
6 & $10,000: 0: 1$ & $\mathrm{Et}_{2} \mathrm{O}$ & 47 & - \\
7 & $10,000: 1: 1$ & $t$-BuOMe & $>99$ & 94 \\
8 & $10,000: 1: 1$ & $\mathrm{THF}$ & 38 & 39 \\
9 & $10,000: 1: 1$ & $\mathrm{PhMe}_{1}$ & 84 & 88 \\
10 & $10,000: 1: 1$ & $\mathrm{CH}_{2} \mathrm{Cl}_{2}$ & 84 & 88 \\
\hline
\end{tabular}

${ }^{a}$ Unless otherwise stated, reactions were carried out using 1a (9.9$10.0 \mathrm{mmol})$ and TMSCN $(12.0 \mathrm{mmol})$ in solvent $(10 \mathrm{~mL})$ with $(S, S, S)-10\left(20 \mathrm{mM}\right.$ in THF) and aqueous $\mathrm{Li}_{2} \mathrm{CO}_{3}(0.1 \mathrm{M})$ at $-78{ }^{\circ} \mathrm{C}$ for $12 \mathrm{~h}$.

${ }^{\mathrm{b}}$ Data for $(R)$-2a were determined by chiral GC analysis.

${ }^{\mathrm{c}}$ Not determined.

The $(S, S, S)-\mathbf{1 0}-\mathrm{Li}_{2} \mathrm{CO}_{3}$ catalyst system was applied to the cyanation of a series of aldehydes 1 (Scheme 4). ${ }^{18}$ All reactions with an $\mathrm{S} / \mathrm{C}$ of 10,000 at $-78{ }^{\circ} \mathrm{C}$ to $70{ }^{\circ} \mathrm{C}$ were completed in 12 to $24 \mathrm{~h}$. Benzaldehydes with an EWG or EDG at the 2', 3', or 4' position were cyanated with excellent enantioselectivity. Among them, the 3'-chloro and 3'-bromo aldehydes were converted to the silylated cyanohydrins in the highest 98\% ee. 1-Naphthaldehyde and heteroaromatic aldehydes were also selectively cyanated under the regular conditions. For the cyanation of aliphatic and $\alpha, \beta$-unsaturated aldehydes, a slightly higher enantioselectivity was obtained in tert-BuOMe than in ether. The primary and secondary alkyl 


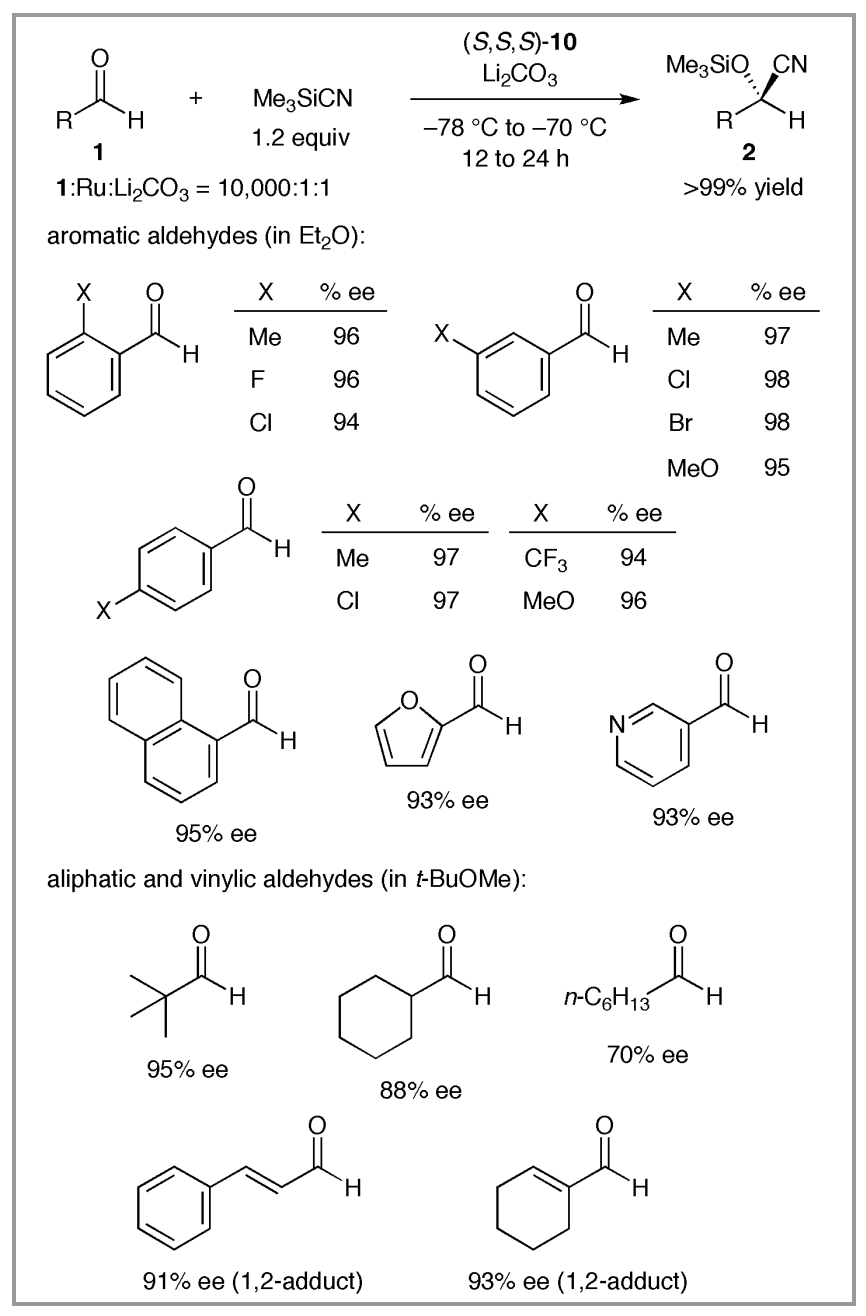

Scheme 4 Asymmetric cyanosilylation of aldehydes 1

aldehydes reacted with high enantioselectivity. A medium ee value of the product was observed in the reaction of a primary alkyl aldehyde. ${ }^{22}$ Only 1,2adducts in $\geq 91 \%$ ee were obtained in the cyanation of the $\alpha, \beta$-unsaturated aldehydes.

The excellent catalytic activity of the $(S, S, S)-10$ $\mathrm{Li}_{2} \mathrm{CO}_{3}$ system led to complete conversion in the cyanosilylation with an $\mathrm{S} / \mathrm{C}$ of 100,000 at $-40{ }^{\circ} \mathrm{C}$ for $24 \mathrm{~h}$ (Scheme 5). ${ }^{23}$ The silylated cyanohydrins derived from benzaldehyde and the 3'-chloro ketone were obtained in $90 \%$ ee and $91 \%$ ee, respectively.

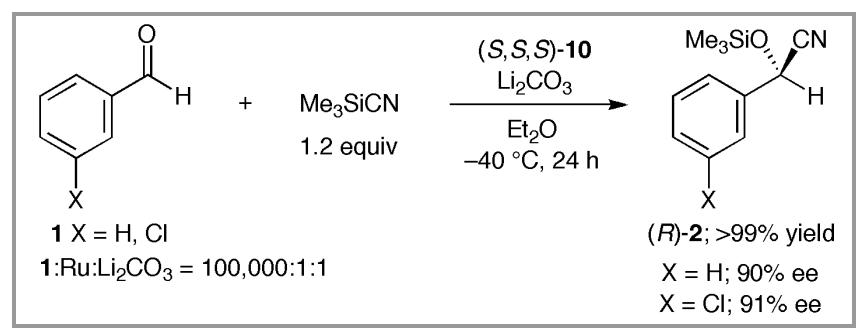

Scheme 5 Asymmetric cyanosilylation with an S/C of 100,000

\subsection{Cyanosilylation of $\alpha$-Keto Esters}

Asymmetric reaction of prochiral ketones and TMSCN is one of the most reliable method to synthesize optically enriched tertiary cyanohydrin derivatives. ${ }^{1,24-28}$ In particular, the reaction of $\alpha$-keto esters, a class of functionalized ketones, affords chiral multi-functionalized cyanated products, which are difficult to make by other methods (see the equation in Table 7). ${ }^{29}$

Table 7 Asymmetric Cyanosilylation of Methyl Benzoylformate (11a) with the 10-PhOLi System ${ }^{\mathrm{a}}$

\begin{tabular}{l}
\multicolumn{5}{c}{$\begin{array}{c}\mathrm{Me}_{3} \mathrm{SiCN} \\
(S, S, S)-10\end{array}$} \\
\cline { 3 - 6 }
\end{tabular}

The $(S, S, S)-\mathbf{1 0}-\mathrm{C}_{6} \mathrm{H}_{5} \mathrm{OLi}$ system exhibited an excellent catalyst performance in the reaction of methyl benzoylformate (11a), a standard aromatic $\alpha$ keto ester, and 2 equiv of TMSCN in tert-BuOMe (Table 7). ${ }^{30}$ PhOLi is a preferable nucleophilic Li compound, the amount of which is easily determined in solution. ${ }^{31}$ The cyanation of 11 a $(0.1 \mathrm{M})$ with an $\mathrm{S} / \mathrm{C}$ of 1000 at $-40{ }^{\circ} \mathrm{C}$ was completed in $3 \mathrm{~h}$ to afford the $R$ silylated cyanohydrin $(R)-12$ a in $97 \%$ ee (entry 1). An excellent ee value of $99 \%$ was achieved in the reaction at $-60{ }^{\circ} \mathrm{C}$, although the reaction rate was slowed (entry 2). To our knowledge, this is the first example of the asymmetric cyanosilylation of $\alpha$-keto esters. $^{32}$ The enantioselectivity tended to decrease slightly with an increase of substrate concentration (entries 2-4). The reaction of $11 \mathrm{a}(0.1 \mathrm{M})$ with an S/C of 10,000 at $-40{ }^{\circ} \mathrm{C}$ required $36 \mathrm{~h}$ for completion (entry 5). The reaction rate increased under a higher substrate concentration of $0.3 \mathrm{M}$ without loss of enantioselectivity (entry 6). The optimized conditions with an S/C of 10,000 were determined to be $0.3 \mathrm{M}$ of 11a at $-50{ }^{\circ} \mathrm{C}$, affording 12a in $98 \%$ ee quantitatively in $18 \mathrm{~h}$ (entry 7). The lower temperature and the higher substrate concentration conditions decreased 
the reaction rate and the enantioselectivity, respectively (entries 8 and 9).

The cyanation catalyzed by the $\mathbf{1 0}-\mathrm{C}_{6} \mathrm{H}_{5} \mathrm{OLi}$ system under the optimized conditions $\left(\mathrm{S} / \mathrm{C}=1000,-60{ }^{\circ} \mathrm{C}\right.$; $\mathrm{S} / \mathrm{C}=10,000,-50{ }^{\circ} \mathrm{C}$ ) was applied to a series of $\alpha$ keto esters (Scheme 6). ${ }^{30}$ The enantioselectivity was highly dependent on the size of the ester moiety $\left(\mathrm{OR}^{2}\right)$. The smallest methyl ester resulted in the highest selectivity. Several methyl benzoylformates with a substituent at the 2', 3', or 4' position were smoothly cyanated to give the desired products in $90 \%-98 \%$ ee. The naphthyl, furyl, and thienyl ketones were also converted with high selectivity. The tert-butyl and cyclohexyl ketones reacted with the same sense of enantioselection as that of benzoylformate. The cyanosilylation of the 1-cyclohexenyl ketone predominantly occurred in a 1,2-fashion to afford the allylic cyanohydrin derivative in $97 \%$ ee. For the cyanation of sterically hindered 2'-methylphenyl and tert-butyl ketones, the use of $\operatorname{Ru}[(S) \text {-phgly }]_{2}[(S)$ xylbinap] $\left((S, S, S)-13\right.$; XylBINAP $=2,2^{\prime}$-bis $($ di-3,5xylylphosphino)-1,1'-binaphthyl) instead of the BINAP complex 10 showed even higher

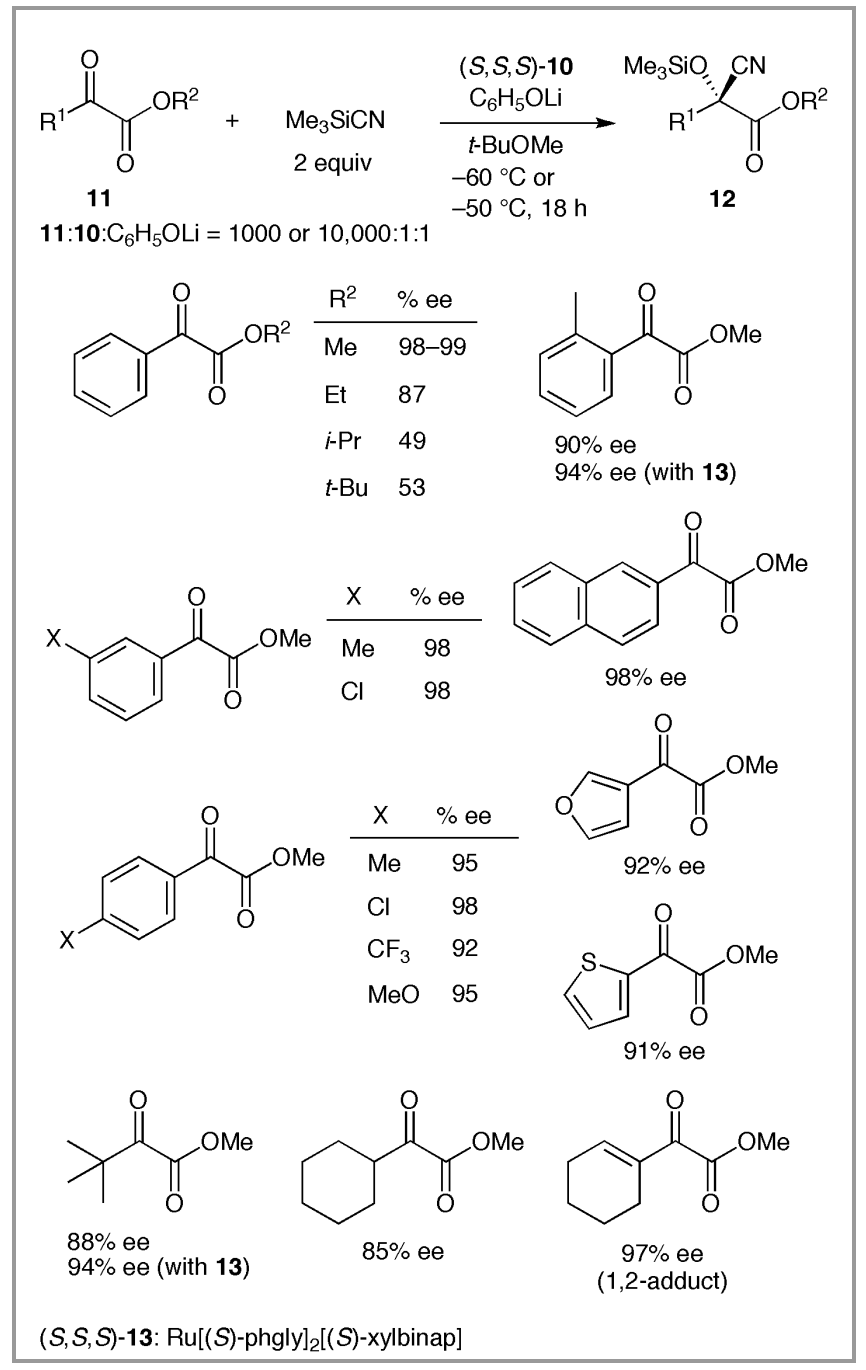

Scheme 6 Asymmetric cyanosilylation of $\alpha$-keto esters 11 enantioselectivity, yielding both cyanohydrin products in $94 \%$ ee. The sterically more demanding structure of XylBINAP seemed to be appropriate for these substrates.

Comparing the enantioselectivity in the cyanosilylation of phenyl (99\%), cyclohexyl (85\%), and 1-cyclohexenyl ketones $(97 \%)$ suggested that the 10-PhOLi catalyst preferably differentiated aryl and alkenyl groups ( $\mathrm{Csp}^{2}$ groups) to alkyl groups ( $\mathrm{Csp}^{3}$ groups) from the $\mathrm{CO}_{2} \mathrm{Me}$ group ( $\mathrm{Csp}^{2}$ group), although the mode of enantioselection is not clear yet.

\section{Asymmetric Hydrocyanation of Aldehydes, $\alpha, \beta$-Unsaturated Ketones, and Aldimines}

\subsection{Hydrocyanation of Aldehydes}

Asymmetric reaction of aldehydes and $\mathrm{HCN}$ (hydrocyanation) is the simplest and most direct method to produce optically active cyanohydrins. ${ }^{1,33}$ $\mathrm{HCN}$ is a highly toxic and volatile (bp. $25.6^{\circ} \mathrm{C}$ ) compound, so that it should be used in a wellventilated fume hood with the utmost care in a laboratory. However, $\mathrm{HCN}$ is produced in the SOHIO acrylonitrile process as a byproduct (about $150 \mathrm{~kg}$ per $1000 \mathrm{~kg}$ of acrylonitrile), ${ }^{34}$ and it is utilized for the production of methyl methacrylate in industrial processes (on a million-ton scale worldwide). ${ }^{35}$ Therefore, $\mathrm{HCN}$ is a useful material especially from a practical viewpoint.

Asymmetric hydrocyanation of aldehydes catalyzed by oxynitrilase is a well-known procedure. .,36,37 $^{-3}$ However, studies on this asymmetric transformation with artificial catalysts have been quite limited. Pioneering works using the cyclic dipeptide cyclo$[(S) \text {-phenylalanyl- }(S) \text {-histidyl }]^{38-40}$ and a Ti(IV) complex with a modified dipeptide ligand ${ }^{41}$ have reported high enantioselectivity, although these catalytic activity $(\mathrm{S} / \mathrm{C}<50)$ and the substrate applicability have room for improvement. Thus, we examined the asymmetric reaction catalyzed by our original chiral $\mathrm{Ru}-\mathrm{Li}$ combined systems.

Benzaldehyde (1a) was selected as a standard substrate (Scheme 7). ${ }^{42} \mathrm{HCN}$ was conveniently

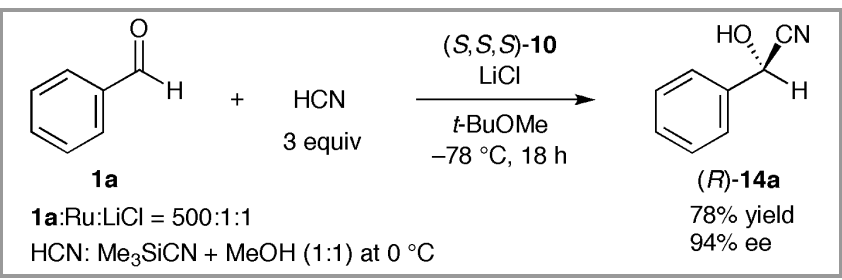

Scheme 7 Asymmetric hydrocyanation of benzaldehyde (1a) with the $10-\mathrm{LiCl}$ system 
prepared in situ by mixing TMSCN and $\mathrm{MeOH}$ in a 1:1 ratio at $0{ }^{\circ} \mathrm{C}$. First, we use the neutral $\mathrm{Ru}[(S)$ phgly $]_{2}[(S)$-binap $]((S, S, S)-10)-\mathrm{LiCl}$ catalyst system to avoid the base-catalyzed achiral cyanation. The reaction of $1 \mathrm{a}$ and $\mathrm{HCN}$ (3 equiv) with an $\mathrm{S} / \mathrm{C}$ of 500 at $-78{ }^{\circ} \mathrm{C}$ for $18 \mathrm{~h}$ afforded the $R$ cyanohydrin $(R)-\mathbf{1 4 a}$ in $94 \%$ ee and in $78 \%$ yield. This result prompted us to prepare the chiral bimetallic complexes $[\mathrm{Li}\{\mathrm{Ru}[(S)$ phgly $]_{2}[(S)$-binap $\left.\left.]\right\}\right] \mathrm{X}((S, S, S)-\mathbf{1 5}: \mathbf{a}: \mathrm{X}=\mathrm{Cl} ; \mathbf{b}: \mathrm{X}=$ Br: Scheme 8), which were the expected active species, and to utilize them as pre-formed catalysts to achieve high reactivity.

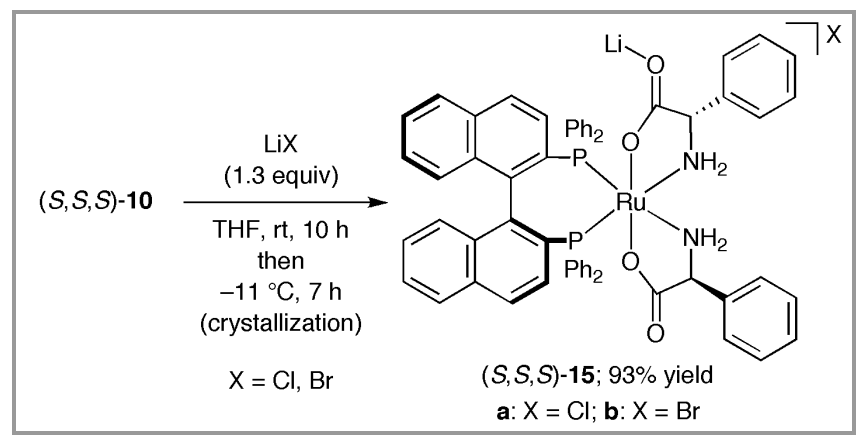

Scheme 8 Preparation of Ru•Li combined complexes 15

The desired complex $(S, S, S)$-15a (yellow crystal) was readily prepared just by mixing $(S, S, S)-\mathbf{1 0}$ and a 1.3 equiv of $\mathrm{LiCl}$ in THF at room temperature and then placing the mixture in a freezer at $-11^{\circ} \mathrm{C}$ (Scheme 8). The $\mathrm{Br}$ complex 15b was obtained as a needle-like crystal with the same procedure. As shown in Figure 3, single-crystal X-ray measurement revealed that $\mathbf{1 5 b}$ has a $\mathrm{Ru}$ center with a distorted octahedral structure in which two carboxylate oxygens bind at the apical positions $\left(\angle \mathrm{O}(1)-\mathrm{Ru}-\mathrm{O}(2)=163^{\circ}\right)$. The $\mathrm{Li}$ cation is placed close to a carbonyl oxygen $(\mathrm{O}(2)-\mathrm{Li}=1.92 \AA)$,

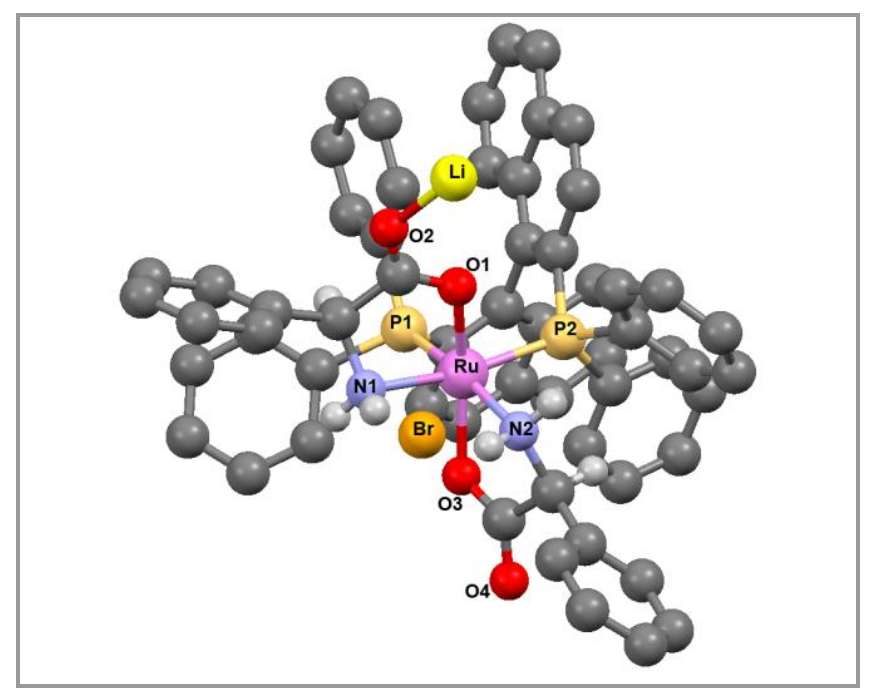

Figure 3 ORTEP drawing of $(S, S, S)$-15b. Selected distances $(\AA)$ and bond angles (deg): Ru-O1 2.108(4), Ru-O3 2.110(4), Ru-N1 2.209(4), Ru-N2 2.117(5), Ru-P1 2.283(1), Ru-P2 2.271(2), LiO2 1.940(1); O1-Ru-O3 162.6(1), N1-Ru-N2 89.3(1), P1-Ru-P2 89.0(5). Only amino and methyne protons of PhGly are shown for clarity. and the $\mathrm{Br}$ anion locates between two nitrogen atoms. The NMR analyses suggested that this structure of $\mathbf{1 5}$ is maintained in the solution phase.

The catalytic efficiency of the bimetallic complex $(S, S, S)$-15a was examined in the hydrocyanation of 1a (Scheme 9). The reaction with an in-situ prepared $\mathrm{HCN}$ at an S/C of 500 was completed in $18 \mathrm{~h}$ to afford $(R)-14 a$ in $95 \%$ ee. The highest level of catalytic activity and enantioselectivity was achieved. The reaction with isolated $\mathrm{HCN}$ prepared and purified as described in the literature ${ }^{43}$ gave a comparable result in the presence of a small amount of triethylamine (1a:amine $=50: 1)$. The amine appeared to catalytically promote the deprotonation from $\mathrm{HCN}$. These results suggest that the reaction is the net hydrocyanation without substantial assistance from silicon compounds when the in-situ prepared $\mathrm{HCN}$ is used. The $\mathrm{Ru}$ complex $\mathbf{1 0}$ or $\mathrm{LiCl}$ alone feebly catalyzed the reaction under the regular conditions.

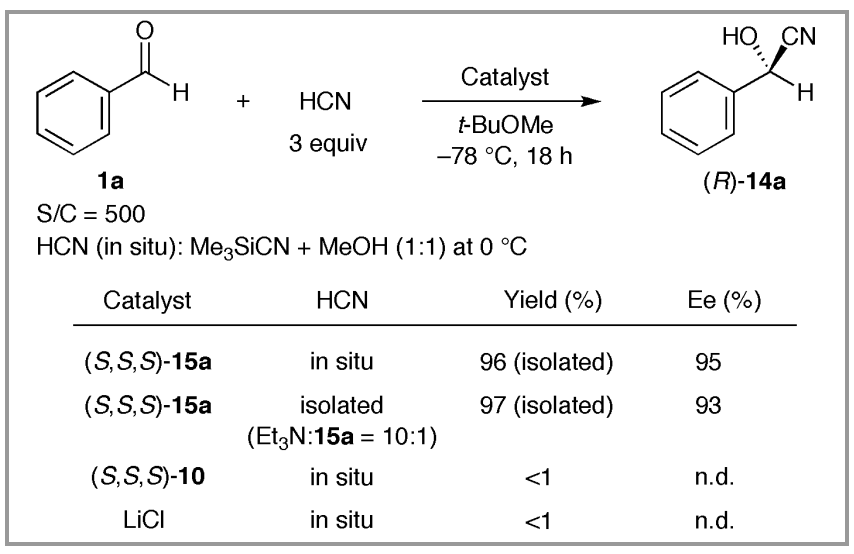

Scheme 9 Asymmetric hydrocyanation of benzaldehyde (1a)

A range of aldehydes was cyanated with the bimetallic catalyst $(S, S, S)-\mathbf{1 5 a}$ to yield the cyanohydrins in high ee. ${ }^{42}$ The results are summarized in Scheme 10. In many cases the reaction with an $\mathrm{S} / \mathrm{C}$ of 500 at $-78^{\circ} \mathrm{C}$ was completed in $18 \mathrm{~h}$ to give the cyanohydrins in $>92 \%$ ee. The excellent ee value of $99 \%$ was observed in the cyanation of 3'-bromobenzaldehyde. The reaction of the 3'-chloro aldehyde with an S/C of 2000 was completed with maintenance of a high level of selectivity. The reaction rate of benzaldehydes with an EDG and 2-furancarbardehyde was slow, but the complete conversion was achieved in the reaction at higher temperature. A few substrates were cyanated with higher enantioselectivity in the presence of the $\mathrm{Br}$ complex 15b than in the presence of the $\mathrm{Cl}$ complex 15a. Cinnamaldehyde was exclusively converted to the 1,2 -adduct in $92 \%$ ee. The degree of enantioselectivity and the 1,2/1,4 selectivity were basically the same as those in the cyanosilylation of aldehydes with the $(S, S, S)-\mathbf{1 0}-\mathrm{Li}_{2} \mathrm{CO}_{3}$ catalyst system, suggesting that the reaction mechanisms of both cyanations are closely related with each other, while the cyanide sources are different. 


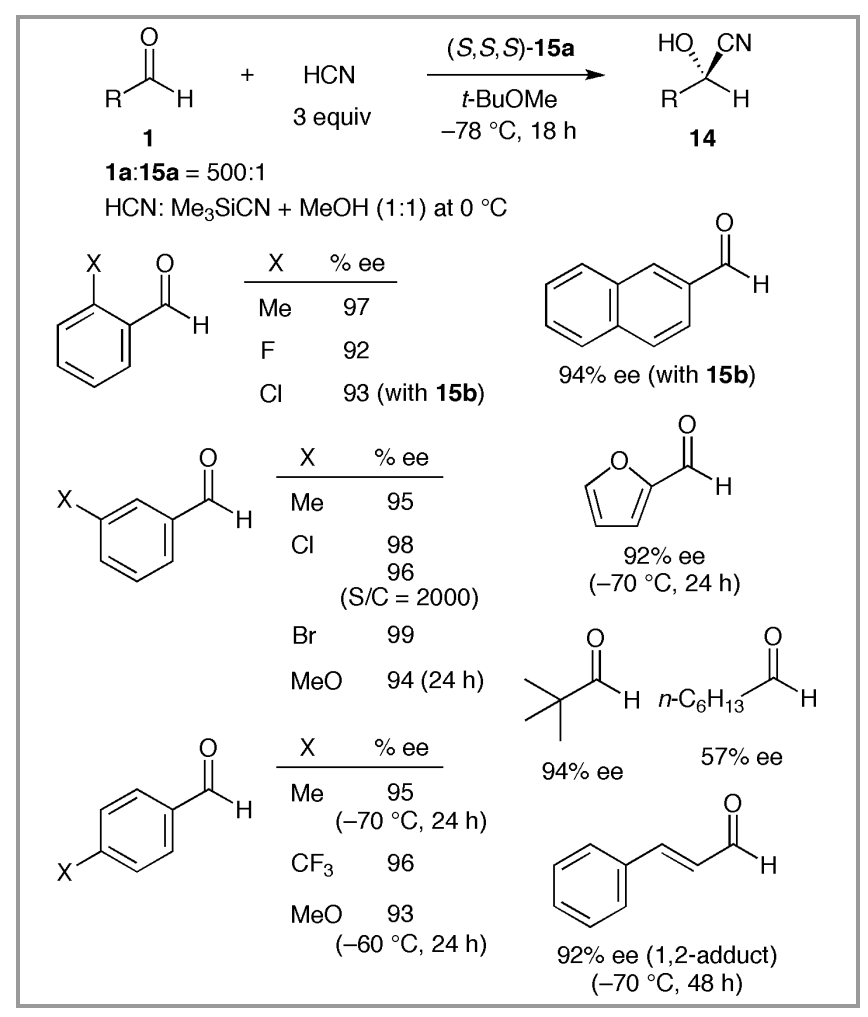

Scheme 10 Asymmetric hydrocyanation of aldehydes 1 with $\mathrm{Ru} \cdot \mathrm{Li}$ combined complexes $\mathbf{1 5}$

\subsection{Conjugate Cyanation of $\alpha, \beta$-Unsaturated Ketones}

As shown in Scheme 10, the 1,2-adduct was the only detectable product in the hydrocyanation of the $\alpha, \beta$ unsaturated aldehyde. ${ }^{44-47}$ The regioselectivity was completely reversed in the reaction of $\alpha, \beta$-unsaturated ketones. When 1-phenyl-2-buten-1-one (16a) and 1.5 equiv of HCN (formed in situ) were reacted with the $(S, S, S)-10-\mathrm{PhOLi}$ catalyst system at an $\mathrm{S} / \mathrm{C}$ of 500 at $25{ }^{\circ} \mathrm{C}$ for $1 \mathrm{~h}$, the $R \beta$-cyano ketone $(R)-17 \mathrm{a}$ was produced in $89 \%$ ee quantitatively (Table 8 , entry 1$){ }^{48}$ No 1,2-adduct was observed. The 1:1 10/PhOLi ratio of the catalyst system showed the best efficiency in terms of reactivity and enantioselectivity (entries $1-5)$. The reactions at $0{ }^{\circ} \mathrm{C}(5 \mathrm{~h})$ and $-20{ }^{\circ} \mathrm{C}(18 \mathrm{~h})$ achieved higher product ee values of $93 \%$ and $97 \%$, respectively (entries 6 and 10). The use of isolated HCN gave the same result (entry 7). ${ }^{49}$ The catalyst

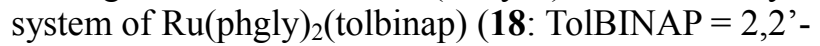
bis(di-4-tolylphosphino)-1,1'-binaphthyl) and PhOLi exhibited a similar efficiency (entry 8). The cyanation with the $(S, S, S)-10-\mathrm{C}_{6} \mathrm{H}_{5} \mathrm{OLi}$ system at an $\mathrm{S} / \mathrm{C}$ of 1000 was also completed in $5 \mathrm{~h}$ with high enantioselectivity (entry 9).

The $(S, S, S)-10-\mathrm{PhOLi}$ catalyst system was broadly applied to the asymmetric 1,4-cyanation of $\alpha, \beta$ -
Table 8 Asymmetric Hydrocyanation of 1-Phenyl-2-buten-1-one (16a) with the 10-PhOLi System ${ }^{\mathrm{a}}$

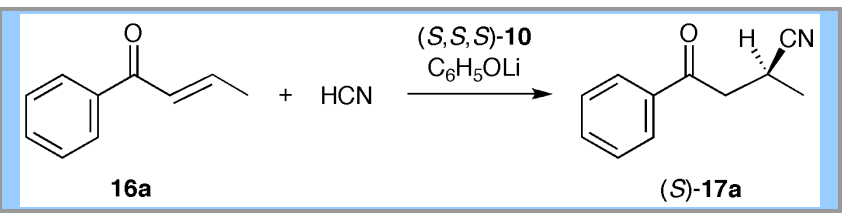

\begin{tabular}{llcccc}
\hline Entry & $\begin{array}{l}\mathbf{1 6 a} / \mathbf{1 0} / \\
\mathrm{C}_{6} \mathrm{H}_{5} \mathrm{OLi}\end{array}$ & $\begin{array}{c}\text { Temp } \\
\left({ }^{\circ} \mathrm{C}\right)\end{array}$ & $\begin{array}{c}\text { Time } \\
(\mathrm{h})\end{array}$ & $\begin{array}{l}\text { Yield } \\
(\%)^{\mathrm{b}}\end{array}$ & $\mathrm{Ee}(\%)^{\mathrm{b}}$ \\
\hline 1 & $500 ; 1 ; 1$ & 25 & 1 & 89 & 89 \\
2 & $500: 0: 1$ & 25 & 1 & 35 & - \\
3 & $500: 1: 0$ & 25 & 1 & $<1$ & n.d. \\
4 & $500: 1: 0.5$ & 25 & 1 & 53 & 90 \\
5 & $500: 1: 2$ & 25 & 1 & $>99$ & 82 \\
6 & $500: 1: 1$ & 0 & 5 & 99 & 93 \\
$7^{\mathrm{c}}$ & $500: 1: 1$ & 0 & 5 & 99 & 93 \\
$8^{\mathrm{d}}$ & $500: 1: 1$ & 0 & 5 & 98 & 90 \\
9 & $1000: 1: 1$ & 0 & 5 & 98 & 90 \\
10 & $500: 1: 1$ & -20 & 18 & 96 & 97 \\
\hline
\end{tabular}

${ }^{a}$ Unless otherwise stated, reactions were conducted using 16a (1.0 $\mathrm{mmol})$ and $\mathrm{HCN}(1.5 \mathrm{mmol})$ in $t$-BuOMe $(6 \mathrm{~mL})$ with $(S, S, S)-10$ (20 mM in THF) and PhOLi (20 mM in THF). HCN was prepared in situ from TMSCN and $\mathrm{MeOH}$ in a 1:1 ratio.

${ }^{\mathrm{b}}$ Data for $(S)$-17a were determined by chiral GC analysis.

${ }^{\mathrm{c}}$ Isolated HCN was used.

${ }^{\mathrm{d}} \mathrm{Ru}[(S) \text {-phgly }]_{2}[(S)$-tolbinap] [(S,S,S)-18] was used instead of $\mathbf{1 0 .}$

unsaturated ketones. ${ }^{48}$ The results are shown in Scheme 11. The phenyl vinyl ketones $\left(\mathrm{R}^{1}=\mathrm{Ph}\right)$ with a $\beta$-alkyl substituent $\left(\mathrm{R}^{2}=\right.$ alkyl) were quantitatively cyanated $\left(\mathrm{S} / \mathrm{C}=500,0{ }^{\circ} \mathrm{C}\right)$ to give the keto nitriles in $90-96 \%$ ee. The size of $\mathrm{R}^{2}$ had a minor influence on the reactivity and enantioselectivity. Thus, the reaction of the $\beta$-isopropyl ketone with an $\mathrm{S} / \mathrm{C}$ of 1000 at $0{ }^{\circ} \mathrm{C}$ and with an $\mathrm{S} / \mathrm{C}$ of 500 at $-20{ }^{\circ} \mathrm{C}$ was completed to afford the product in $92 \%$ ee and $98 \%$ ee, respectively. The reactivity of chalcone, a $\beta$-phenyl ketone, was somewhat lower, but the stereoselectivity was still high. ${ }^{50}$ The phenyl vinyl ketones with an EDG or EWG on the phenyl ring were cyanated with high enantioselectivity of $>90 \%$, except in the case of the 2'-chlorophenyl ketone. The 4'- $\mathrm{CF}_{3}$-substituted ketone reacted with the highest reaction rate. The cyanation of 2'-naphthyl, furyl, and thienyl ketones showed the same level of reactivity and selectivity. The reactivity of 3-hepten-2-one, an aliphatic substrate, was relatively low, but complete conversion was achieved by using the 18-PhOLi system with an $\mathrm{S} / \mathrm{C}$ of 200 to give the $\beta$-keto nitrile in $93 \%$ ee. The sense of enantioselectivity was the same as that of the phenyl ketone 16a.

When the 18-PhOLi catalyst system was applied to the hydrocyanation of dialkenyl ketone $\mathbf{1 9}(\mathrm{S} / \mathrm{C}=200$, $0{ }^{\circ} \mathrm{C}$ ), the mono-cyano ketone $\mathbf{2 0}$ was obtained in $96 \%$ ee (Scheme 12). Neither a regioisomer nor a di-cyano ketone was observed. This selectivity was expected to be useful for the synthesis of multi-functionalized chiral ketones. 


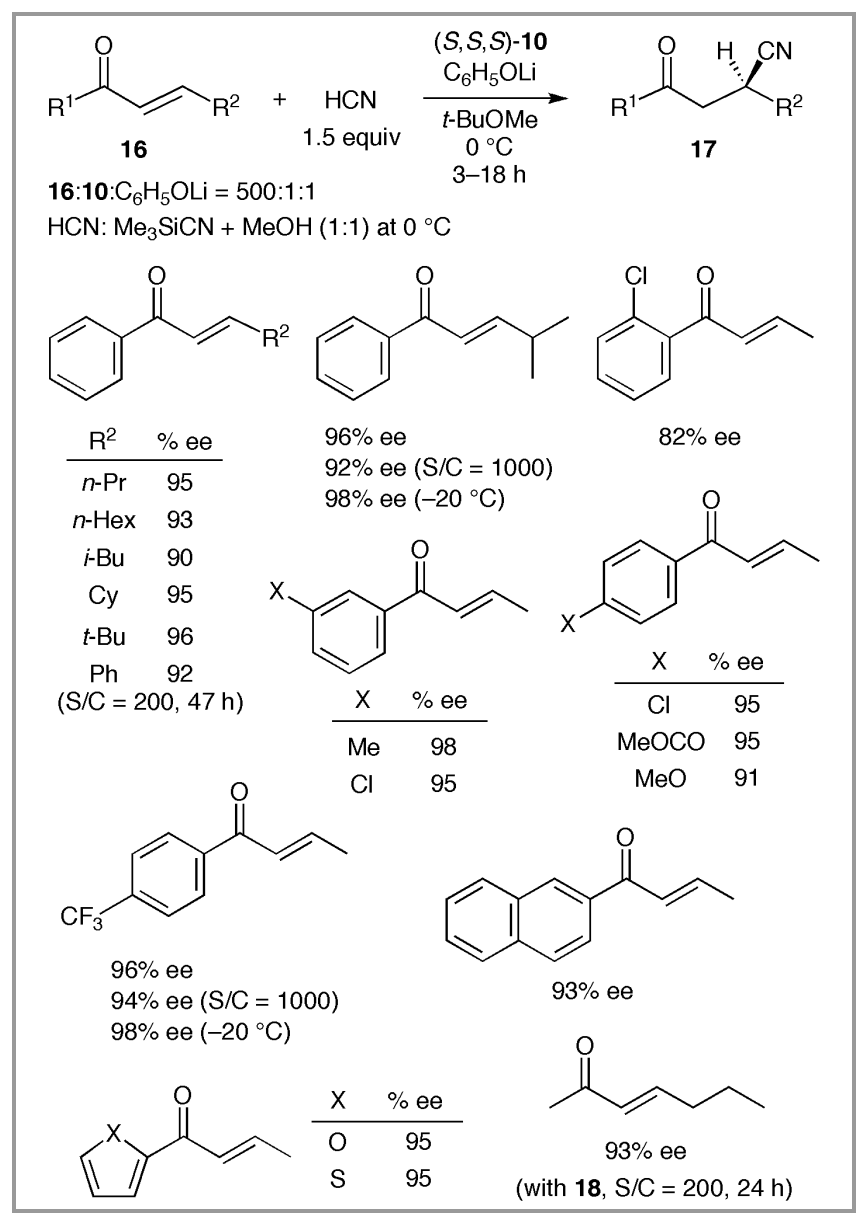

Scheme 11 Asymmetric hydrocyanation of $\alpha, \beta$-unsaturated ketones 16 into $\beta$-cyano ketones 17

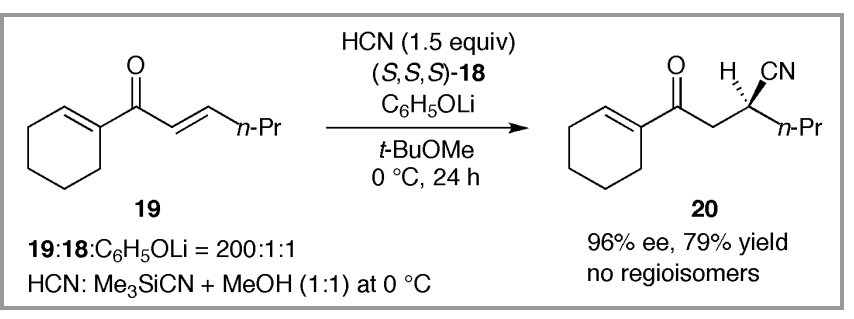

Scheme 12 Regioselective cyanation of dienone 19

The robustness of the $\mathrm{Ru}$ complex $\mathbf{1 0}$ enabled us to recover it with silica-gel column chromatography after the reaction. ${ }^{48}$ The recovered $\mathbf{1 0}$ with an addition of PhOLi showed catalytic efficiency comparable to that of the fresh catalyst. Thus, the complex $\mathbf{1 0}$ could be used five times in the cyanation with an initial $\mathrm{S} / \mathrm{C}$ of 500, as shown in Table 9. Five different unsaturated ketones were converted successfully by using the same $\mathrm{Ru}$ complex $($ total TON $=2500)$.

\subsection{Strecker-type Reaction}

Asymmetric hydrocyanation of imines (Strecker-type reaction) producing optically active $\alpha$-amino nitriles, which are direct precursors of $\alpha$-amino acids, is the indispensable synthetic procedure. ${ }^{1,51,52}$ The wide substrate-applicability is required for the synthesis of
Table 9 Recycled Use of $\mathbf{1 0}$ in the Hydrocyanation of $\mathbf{1 6}$

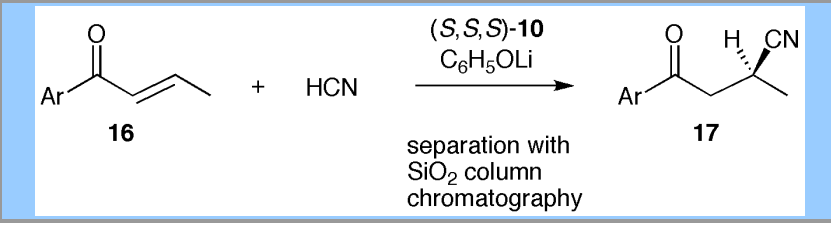

\begin{tabular}{llccc}
\hline $\begin{array}{l}\text { Run } \\
\text { number }^{\text {b }}\end{array}$ & $\mathrm{Ar}$ & $\begin{array}{l}\text { Time } \\
(\mathrm{h})\end{array}$ & $\begin{array}{c}\text { Yield } \\
(\%)^{\mathrm{c}}\end{array}$ & Ee (\%) \\
\hline 1 & $4-\mathrm{CH}_{3} \mathrm{OCOC}_{6} \mathrm{H}_{4}$ & 3 & 96 & 93 \\
2 & $2-\mathrm{NaPh}_{3}$ & 12 & 96 & 90 \\
3 & $3-\mathrm{ClC}_{6} \mathrm{H}_{4}$ & 5 & 98 & 96 \\
4 & $4-\mathrm{ClC}_{6} \mathrm{H}_{4}$ & 3 & 95 & 95 \\
$5^{\mathrm{e}}$ & $3-\mathrm{CH}_{3} \mathrm{OC}_{6} \mathrm{H}_{4}$ & 12 & 99 & 96 \\
\hline
\end{tabular}

${ }^{\mathrm{a}}$ Reactions were conducted using $16(8.2 \mathrm{mmol})$ and $\mathrm{HCN}(11.8$ $\mathrm{mmol})$ in $t$-BuOMe $(48 \mathrm{~mL})$ at $0^{\circ} \mathrm{C}$ with a solid $(S, S, S)-\mathbf{1 0}$ and PhOLi (50 mM in THF). 16/10/PhOLi = 1:1:1 (initial). HCN was prepared in situ from TMSCN and $\mathrm{MeOH}$ in a $1: 1$ ratio.

${ }^{\mathrm{b}}$ Number of times the catalyst was used.

${ }^{\mathrm{c}}$ Isolated yield.

${ }^{\mathrm{d}}$ Determined by chiral GC or HPLC analysis.

${ }^{\mathrm{e}}$ Reaction using 16 (3.2 $\left.\mathrm{mmol}\right)$ and $\mathrm{HCN}$ (4.8 mmol) in $t$-BuOMe (19 mL).

a variety of the proteinogenic and the nonproteinogenic amino acids. When two enantiomers of the catalysts are available, the natural type and the unnatural type of amino acids can be selectively synthesized.

We have revealed that the 10-PhOLi system efficiently catalyzed asymmetric conjugate addition of $\mathrm{HCN}$ to $\alpha, \beta$-unsaturated ketones $\mathbf{1 6}$ under mild temperature conditions of $-20{ }^{\circ} \mathrm{C}$ to $0{ }^{\circ} \mathrm{C}$. We therefore expected that the $\pi$-isoelectronic $N$ alkoxycarbonyl aldimines $\mathbf{2 1}$ could be cyanated with high reactivity and enantioselectivity by using the same catalyst system under the mild conditions (Scheme 13).

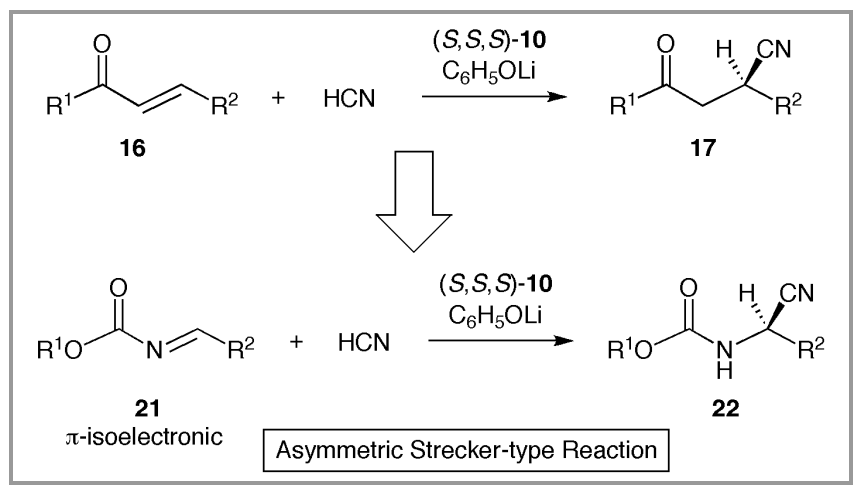

Scheme 13 Asymmetric hydrocyanation of $\alpha, \beta$-unsaturated ketones and $N$-protected imines

The cyanation of $N$-benzyloxycarbonyl (Cbz) imine 21a derived from benzaldehyde according to the reported method ${ }^{53}$ was selected as the typical reaction to optimize the reaction conditions (Table 10). The aldimine 21a and a 3 equiv of HCN (in situ) smoothly 
Table 10 Asymmetric Hydrocyanation of $\mathrm{N}-\mathrm{Cbz}$ Aldimine 21a with the 10-PhOLi System ${ }^{\mathrm{a}}$

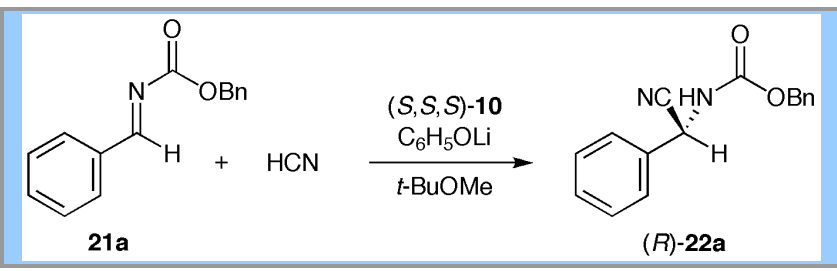

\begin{tabular}{lrrccc}
\hline Entry & S/C & $\begin{array}{l}\text { Temp } \\
\left({ }^{\circ} \mathrm{C}\right)\end{array}$ & Time (h) & $\begin{array}{c}\text { Yield } \\
(\%)^{\mathrm{b}}\end{array}$ & Ee $(\%)^{\mathrm{c}}$ \\
\hline 1 & 500 & 0 & 0.5 & 99 & 97 \\
2 & 500 & -20 & 0.5 & 98 & 98 \\
3 & 500 & 25 & 0.5 & 98 & 89 \\
$4^{\mathrm{d}}$ & 500 & 0 & 0.5 & 98 & 96 \\
$5^{\mathrm{e}}$ & 5000 & 0 & 2 & 95 & 96 \\
\hline
\end{tabular}

${ }^{\mathrm{a}}$ Unless otherwise stated, reactions were conducted using 21a (1.0 mmol, $0.15 \mathrm{M})$ and $\mathrm{HCN}(3.0 \mathrm{mmol})$ in $t$-BuOMe with a solid $(S, S, S)-\mathbf{1 0}$ and PhOLi (100 mM in THF). 10:PhOLi $=1: 1 . \mathrm{HCN}$ was prepared in situ from TMSCN and $\mathrm{MeOH}$ in a 1:1 ratio.

${ }^{\mathrm{b}}$ Isolated yield of $\mathbf{2 2 a}$.

${ }^{c}$ Determined by chiral HPLC analysis.

${ }^{\mathrm{d}}$ Isolated HCN was used.

${ }^{\mathrm{e}}$ Reaction using $10 \mathrm{mmol}$ of $\mathbf{2 1 a}$.

reacted in the presence of the $(S, S, S)-\mathbf{1 0}-\mathrm{PhOLi}$ catalyst system with an $\mathrm{S} / \mathrm{C}$ of 500 at $0{ }^{\circ} \mathrm{C}$ to afford the $R$ amino nitrile $(R)-\mathbf{2 2 a}$ in $97 \%$ ee quantitatively in $30 \mathrm{~min}$ (entry 1). ${ }^{54}$ The reaction at $-20{ }^{\circ} \mathrm{C}$ also completed in $30 \mathrm{~min}$ to give 22a in $98 \%$ ee (entry 2). The high ee value of $89 \%$ was obtained even at $25^{\circ} \mathrm{C}$ (entry 3 ). The use of isolated $\mathrm{HCN}$ gave a comparable result to that with the in situ-formed HCN (entry 4). The high catalytic efficiency of the 10-PhOLi system achieved complete conversion in the cyanation with an $\mathrm{S} / \mathrm{C}$ of 5000 at $0{ }^{\circ} \mathrm{C}$ in $2 \mathrm{~h}$ to yield 22a in $96 \%$ ee (entry 5).

The Strecker-type reaction with the 10-PhOLi catalyst system was applied to a variety of $N$-protected aldimines (Scheme 14). ${ }^{54}$ As we expected, $N$-tertbutoxycarbonyl (Boc) and $N$-benzoyl (Bz) imines were cyanated with a high level of enantioselectivity. The reactivity and selectivity were significantly decreased in the reaction of the $N$-benzyl (Bn) imine. Various aromatic, heteroaromatic, and aliphatic $N-\mathrm{Cbz}$ aldimines were cyanated with high reactivity and enantioselectivity. An excellent ee value of $99 \%$ was obtained in the reaction of 3 -bromo imine at $-20^{\circ} \mathrm{C}$. The reaction of the sterically hindered tert-butyl imine with an $\mathrm{S} / \mathrm{C}$ of 5000 at $0{ }^{\circ} \mathrm{C}$ was completed in $2 \mathrm{~h}$. The 4'- $\mathrm{CF}_{3}$-phenyl imine and $n$-propyl imine were reacted with low to moderate enantioselectivity, possibly due to the competitive base-catalyzed achiral cyanation.

This problem was solved by the use of the less basic $\mathrm{Ru} \cdot \mathrm{Li}$ bimetallic catalyst 15a (Scheme 15). The ee values of the products were significantly increased: for 4 ' $-\mathrm{CF}_{3}$-phenyl imine, from $19 \%$ to $97 \%$; for $n$ propyl imine, from $80 \%$ to $96 \%$; and for cyclohexyl

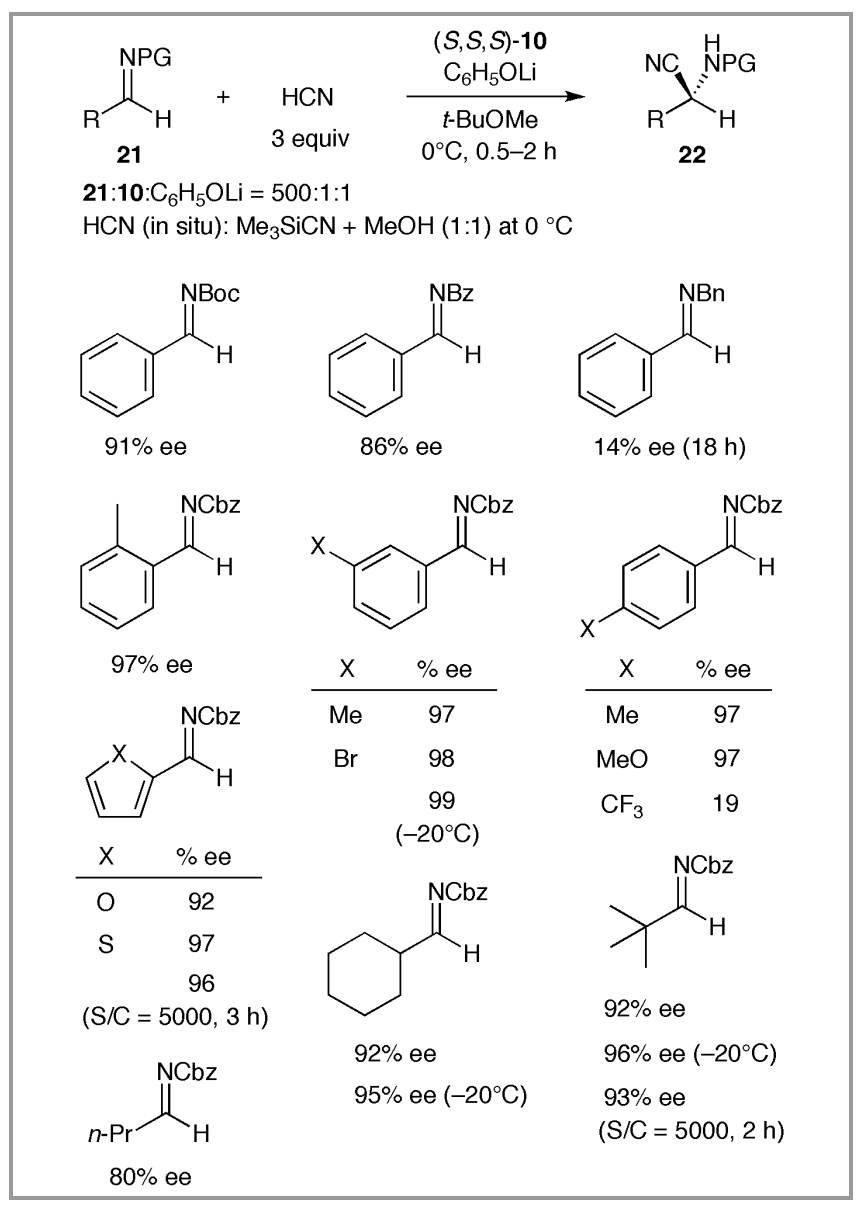

Scheme 14 Asymmetric hydrocyanation of $N$-protected aldimines 21 with the 10-PhOLi system

imine; from $92 \%$ to $94 \%$. In particular, the excellent enantioselectivity in the reaction of $n$-alkyl imine was noteworthy. ${ }^{55}$

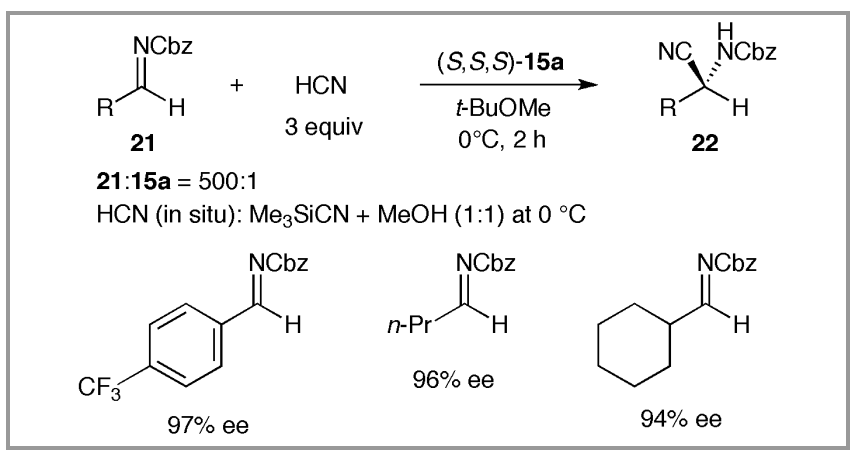

Scheme 15 Asymmetric hydrocyanation of $N$-Cbz aldimines 21 with the Ru$\cdot$ Li combined complex $\mathbf{1 5 a}$

The cyanated product $(R)-22 \mathrm{a}$ in $97 \%$ ee was hydrolyzed under the acidic conditions at $110{ }^{\circ} \mathrm{C}$ to give $(R)$-phenylglycine $((R)-23)$ in $96 \%$ ee and $94 \%$ yield (Scheme 16). The $R$ product in $96 \%$ ee was applied for the synthesis of $\mathrm{Ru}[(R) \text {-phgly }]_{2}[(R)$-binap $]$ $((R, R, R)-\mathbf{1 0})$. The diastereomeric byproducts were easily removed with a silica-gel preparative TLC to afford pure $(R, R, R)-\mathbf{1 0}$. 


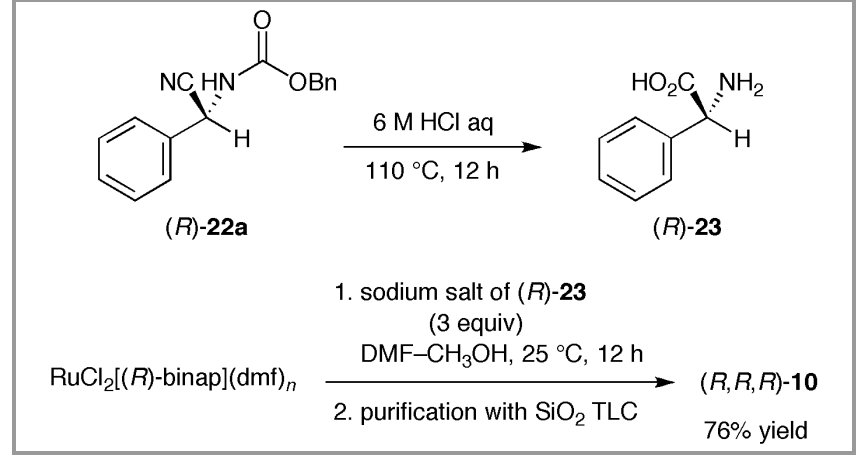

Scheme 16 Preparation of $(R)$-phenylglycine $((R)-23)$ and the application to formation of $(R, R, R)-\mathbf{1 0}$

5

$\begin{array}{llr}\begin{array}{l}\text { Mechanistic } \\ \text { Cyanosilylation }\end{array} & \begin{array}{l}\text { Considerations } \\ \text { of Aldehydes }\end{array} & \text { for } \\ \text { Ketones } & \text { and }\end{array}$

\subsection{Achiral Reaction Catalyzed by LiCl}

The reaction of carbonyl compounds and TMSCN was efficiently catalyzed by $\mathrm{LiCl}$ as discussed in Section 2 . $\mathrm{LiCl}$ is an inorganic salt, but it is soluble in several organic polar solvents and acts as a $\mathrm{Cl}$ anion source. ${ }^{56}$ Therefore, $\mathrm{LiCl}$ probably acts as a nucleophilic (Lewis basic) catalyst to activate the reagent TMSCN. The ${ }^{13} \mathrm{C}$ NMR (THF- $d_{8}$ ) measurement suggested that $\mathrm{LiCl}$ reacted with TMSCN $\left(\mathrm{CH}_{3} ; \delta=-2.07\right)$ to form $\mathrm{Li}\left[\mathrm{Me}_{3} \mathrm{SiCl}(\mathrm{NC})\right](\mathbf{2 4})$ showing a $\mathrm{CH}_{3}$ signal at $\delta 1.93$ (Scheme 17). ${ }^{6}$ This NMR behavior was consistent with the observation in the measurement of a mixture of 18-crown-6, $\mathrm{KCN}$, and TMSCN, indicating the $\mathrm{CH}_{3}$ signal at $\delta 1.91$, which corresponded to the pentavalent $\left[\mathrm{Me}_{3} \mathrm{Si}(\mathrm{NC})_{2}\right]^{-}$reported in the literature. ${ }^{57}$ $\mathrm{No} \mathrm{CH}_{3}$ signal of TMSCl at $\delta 3.20$ was detected. The nucleophilic property of the reactive species was confirmed by Hammett experiments ${ }^{58}$ for the cyanosilylation of 4'-substituted benzaldehydes catalyzed by $\mathrm{LiCl}$. Thus, the relative rates toward the reaction of benzaldehyde were plotted against the $\sigma_{p}$ constant, showing a linear relationship with a $\rho$ value of +1.24 .

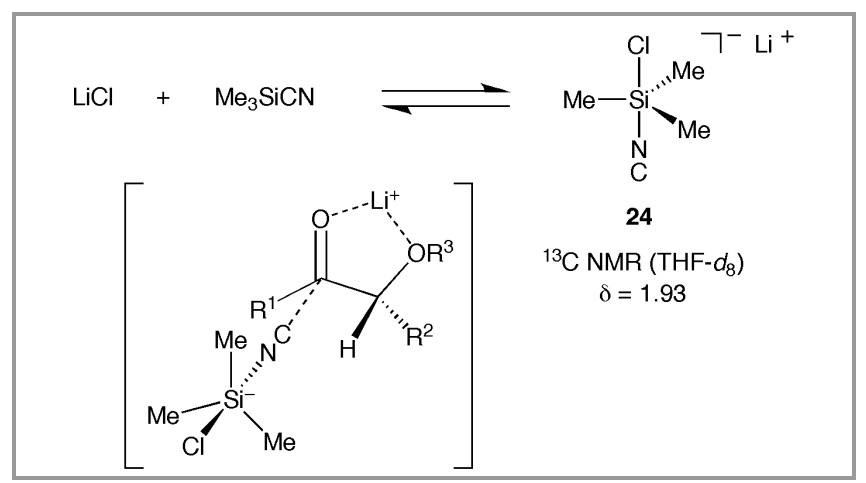

Scheme 17 Plausible active species $\mathbf{2 4}$ and the reaction pathway in the cyanosilylation of $\alpha$-alkoxy ketones catalyzed by $\mathrm{LiCl}$
The high anti-selectivity in the cyanation of 2benzyloxypropiophenone (8a) described in Scheme 2 of Section 2 was interpreted by using a chelation intermediate as shown in Scheme $17 .^{12,13}$ This observation strongly suggested that $\mathrm{LiCl}$ also behaved as a source of Lewis acidic Li cation to activate the carbonyl moiety of substrates.

\subsection{Asymmetric Reaction with the Chiral Ru-Li Combined Catalyst}

The combined system of Ru(phgly) $)_{2}$ (binap) (10) and PhOLi showed high catalytic activity and enantioselectivity in the cyanation of $\alpha$-keto esters, as mentioned in Section 3.3. The Ru complex 10 alone exhibited feeble catalytic activity. ESI massspectroscopic analysis of a mixture of $\mathbf{1 0}(\mathrm{m} / \mathrm{z}$ 1024), PhOLi, and TMSCN in a 1:1:10 ratio showed prominent signals centered at $\mathrm{m} / \mathrm{z}$ 1031, which correspond to the $\mathrm{Ru}-\mathrm{Li}$ combined species $[\mathbf{1 0} \cdot \mathrm{Li}]^{+30}$ The same signals were detected in the measurement of the ${ }^{10}-\mathrm{Li}_{2} \mathrm{CO}_{3}$ system. ${ }^{18}{ }^{1} \mathrm{H}$ and ${ }^{13} \mathrm{C}$ NMR measurements of this 1:1:10 mixture suggested that $\mathrm{PhO}^{-}$quantitatively reacted with TMSCN to give TMSOPh and $\mathrm{CN}^{-}$(Figure 4, (1)-(a) and (2)-(a)). The pentacoordinate $\mathrm{Si}$ species $\left[\mathrm{Me}_{3} \mathrm{Si}(\mathrm{NC})_{2}\right]^{-}$was not observed, while an excess
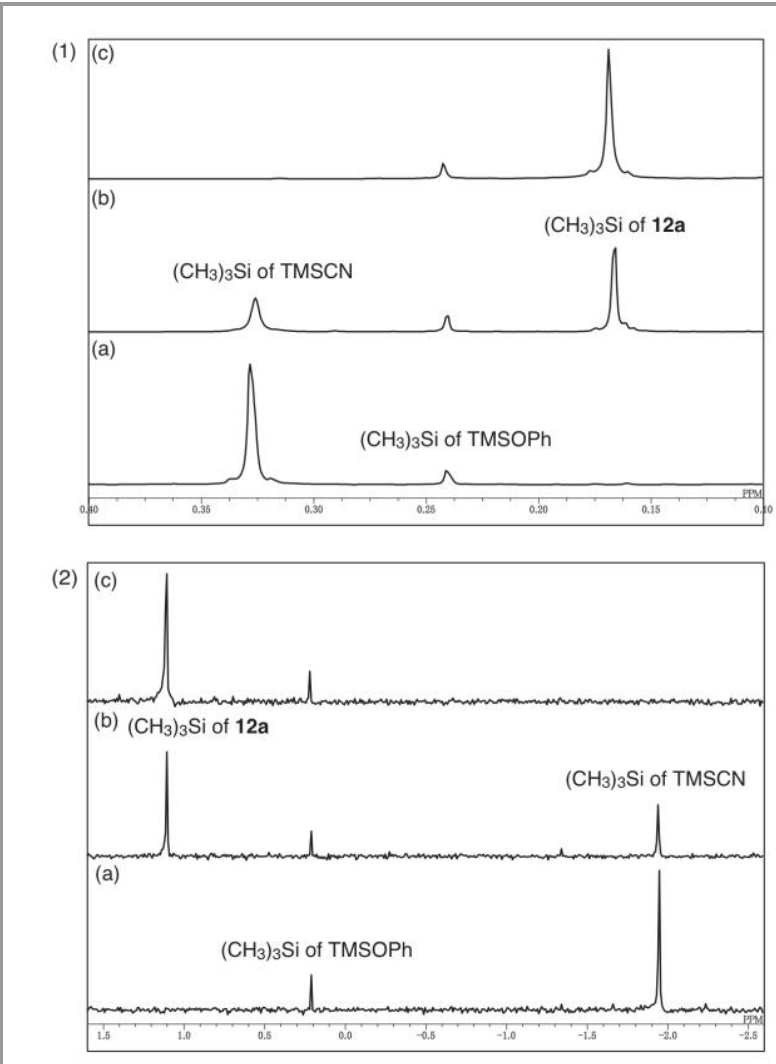

Figure $4{ }^{1} \mathrm{H}$ NMR (1) and ${ }^{13} \mathrm{C}$ NMR (2) spectra: (a) a 1:1:10 mixture of $(S, S, S)-\mathbf{1 0}, \mathrm{PhOLi}$, and TMSCN; (b) a 1:1:10:3 mixture of $(S, S, S)-\mathbf{1 0}, \mathrm{PhOLi}, \mathrm{TMSCN}$, and 11a; (c) a 1:1:10:10 mixture of $(S, S, S)-\mathbf{1 0}$, PhOLi, TMSCN, and 11a 
amount of TMSCN existed in this mixture. An $\alpha$-keto ester 11a smoothly reacted in this system to give the silylated cyanohydrin 12a (Figure 4, (1)-(b) and (2)(b)). When a sufficient amount of 11a was added to this mixture, the signal of TMSCN disappeared with the increase of the cyanated product 12a (Figure 4, (1)-(c) and (2)-(c)). The peak of TMSOPh remained intact during this procedure.

Scheme 18 illustrates the plausible reaction pathway for the cyanosilylation of $\alpha$-keto esters 11 catalyzed by the Ru complex 10-PhOLi system, according to the above-mentioned experimental data. Nonproductive and minor pathways are not considered here. The complex 10, PhOLi, and TMSCN afford the bimetallic complex $[10 \cdot \mathrm{Li}] \mathrm{CN}$ accompanied by TMSOPh. The structure of $[\mathbf{1 0} \cdot \mathrm{Li}]^{+}$ is thought to be the same as that of $\left[\mathrm{Li}\left\{\mathrm{Ru}(\text { phgly })_{2}(\right.\right.$ binap $\left.\left.)\right\}\right] \mathrm{Br}$ (15b: see Figure 3$) .{ }^{42}$ When $\mathrm{LiCl}$ is used instead of $\mathrm{PhOLi},\left[\mathrm{Me}_{3} \mathrm{SiCl}(\mathrm{NC})\right]^{-}$ is a possible counter anion. The keto ester $\mathbf{1 1}$ smoothly reacts with $[10 \cdot \mathrm{Li}] \mathrm{CN}$, in which $[10 \cdot \mathrm{Li}]^{+}$ effectively acts as a chiral Lewis acid, affording the cyanated anion with $[\mathbf{1 0} \cdot \mathrm{Li}]^{+}$. The cyanated anion spontaneously reacts with TMSCN to give the silylated cyanohydrin $\mathbf{1 2}$ with the regeneration of the active species $[10 \cdot \mathrm{Li}] \mathrm{CN}$. This proposed pathway is consistent with the result that the 10- $\mathrm{Li}$ compound system catalyzes the hydrocyanation with high reactivity and enantioselectivity as described in Section 4.

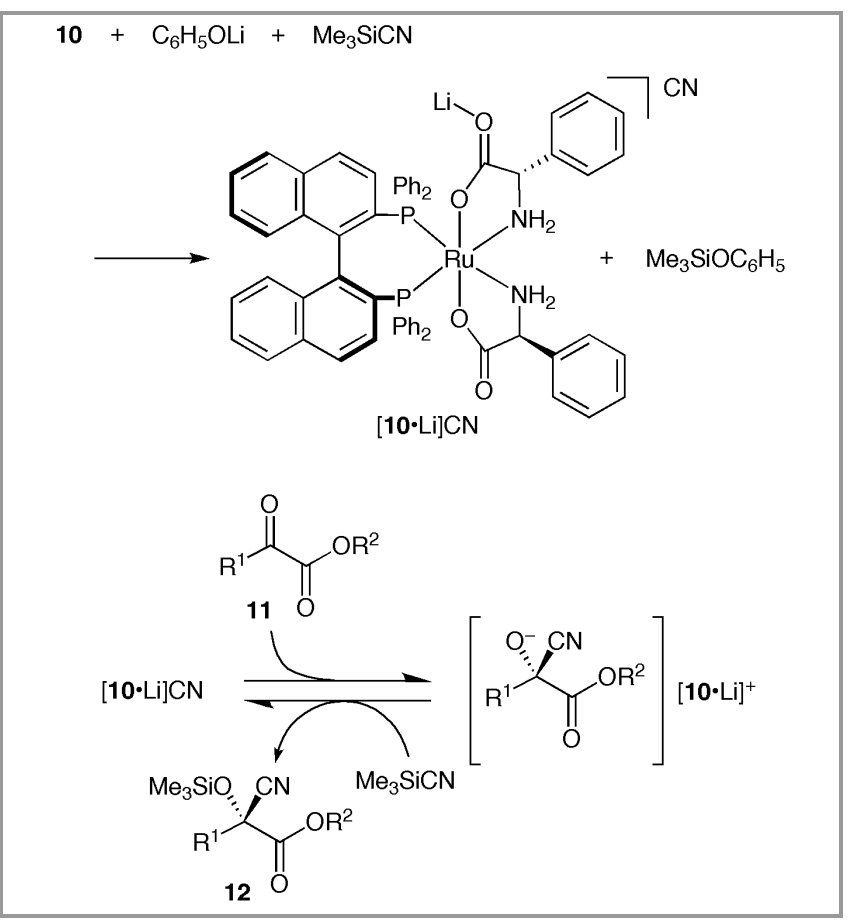

Scheme 18 Plausible mechanism for cyanosilylation of $\alpha$-keto esters $\mathbf{1 1}$

\section{Conclusion}

LiCl, a simple Li salt, shows exceptionally high catalytic activity in the cyanosilylation of aldehydes and functionalized ketones with hetero-atom groups. The reaction with a substrate-to-catalyst molar ratio $(\mathrm{S} / \mathrm{C})$ of 100,000 at about $25^{\circ} \mathrm{C}$ completes within $48 \mathrm{~h}$ in the best cases. The reactivity of unfunctionalized acetophenone is relatively low, but the cyanation with an S/C of 100 quantitatively affords the desired product in $3 \mathrm{~h}$.

The combined catalyst systems consisting of $\mathrm{Ru}[(S)$ phgly $]_{2}[(S)$-binap $]((S, S, S)-\mathbf{1 0})$ and $\mathrm{Li}$ compounds exhibit excellent reactivity and enantioselectivity in the cyanosilylation and hydrocyanation of aldehydes, $\alpha$-keto esters, $\alpha, \beta$-unsaturated ketones, and $N$ protected aldimines. The $\mathrm{Ru}$ complex $\mathbf{1 0}$ is considered to act as the "chiral template" for modification of Li cation. The chiral structure of the catalyst system is easily constructed by complexation of the PhGly and BINAP ligands on the Ru center.

The reaction of aldehydes and TMSCN (cyanosilylation) is catalyzed by the $10-\mathrm{Li}_{2} \mathrm{CO}_{3}$ system in ether solvents to afford the silylated cyanohydrins in up to $98 \%$ ee. The cyanosilylations of benzaldehyde (1a) with an $\mathrm{S} / \mathrm{C}$ of 10,000 at $-78{ }^{\circ} \mathrm{C}$ and 100,000 at $-40{ }^{\circ} \mathrm{C}$ are completed in $12 \mathrm{~h}(97 \%$ ee) and $24 \mathrm{~h}(90 \%$ ee $)$, respectively. The high catalytic activity of this system is notable, although the low reaction temperature is a disadvantage from a practical viewpoint. When the 10-PhOLi catalyst system is utilized at $-60{ }^{\circ} \mathrm{C}(\mathrm{S} / \mathrm{C}=1000)$, a series of $\alpha$-keto esters is cyanated to produce the tertiary cyanohydrin derivatives with multi functionalities in up to $99 \%$ ee quantitatively. The transformation with an $\mathrm{S} / \mathrm{C}$ of 10,000 at $-50 \quad{ }^{\circ} \mathrm{C}$ also completes with high enantioselectivity. This is the first example of the highly enantioselective cyanosilylation of $\alpha$-keto esters to our knowledge.

$\mathrm{HCN}$ is a toxic compound, but it is known to be a useful and practical synthetic material. Asymmetric reaction of aldehydes and $\mathrm{HCN}$ (hydrocyanation) is achieved by using the preformed catalyst $[\operatorname{Li}\{\operatorname{Ru}[(S)$ phgly $]_{2}[(S)$-binap $\left.\left.]\right\}\right] \mathrm{Cl}((S, S, S)$-15a) with an $\mathrm{S} / \mathrm{C}$ as high as 2000 at $-78{ }^{\circ} \mathrm{C}$ to afford the cyanohydrins in up to $99 \%$ ee. The degree and sense of enantioselectivity are the same as those in the cyanosilylation of aldehydes. The wide scope of substrates for this hydrocyanation is noteworthy, althogh the low reaction temperature is a drawback to be improved.

Enantioselective conjugate cyanation of $\alpha, \beta-$ unsaturated ketones into the $\beta$-cyano ketones is also catalyzed by the 10-PhOLi system. The reaction is conducted with an S/C of 200 to 1000 at $-20{ }^{\circ} \mathrm{C}$ to $0{ }^{\circ} \mathrm{C}$ to yield the chiral nitriles in $82 \%$ ee to $98 \%$ ee. 
Significantly low reaction temperature is not required in this reaction. No 1,2-addition products are observed under the regular reaction conditions. The $\mathrm{Ru}$ complex $\mathbf{1 0}$ is so robust that it can be recovered by column chromatography. Therefore, it is reusable for this reaction, achieving a total turnover number of $2500(\mathrm{~S} / \mathrm{C}=500,5$ times $)$.

The catalyst system 10-PhOLi and 15a are effective for the asymmetric hydrocyanation of $\mathrm{N}$ benzyloxycarbonyl aldimines (Strecker-type reaction). The reaction is carried out with an S/C of 500 to 5000 at $-20{ }^{\circ} \mathrm{C}$ to $0{ }^{\circ} \mathrm{C}$, resulting in the amino nitriles in $92 \%$ ee and $99 \%$ ee quantitatively. This transformation is widely applied to the primary, secondary, and tertiary alkyl imines as well as the aryl and heteroaryl substrates. Therefore, this system is among the best catalysts for the hydrocyanation of imines in terms of reactivity, enantioselectivity, and the substrate scope to our knowledge.

A reaction pathway of the cyanosilylation of $\alpha$-keto esters is proposed based on the spectral analysis data. The nature of active species could depend on the Lewis basicity (or nucleophilicity) of the $\mathrm{Li}$ compound. Thus, TMSCN and $\mathrm{LiCl}$ form the pentavalent $\mathrm{Si}$ species $\mathrm{Li}\left[\mathrm{Me}_{3} \mathrm{SiCl}(\mathrm{NC})\right]$, while the reaction of TMSCN and PhOLi affords TMSOPh and $\mathrm{LiCN}$. The cyanosilylation with the 10-PhOLi system is proposed to proceed with the $\mathrm{Ru}-\mathrm{Li}$ combined complex $\left[\mathrm{Li}\left\{\mathrm{Ru}(\text { phgly })_{2}\right.\right.$ (binap) $\left.\}\right] \mathrm{CN}$ as the active catalytic species.

\section{Acknowledgment}

We would like to gratefully acknowledge our collaborators at Hokkaido University. Their names are given in the cited publications. This work was supported by Grants-in-Aid from the Japan Society for the Promotion of Science (No. 21350048) and the Japan Science and Technology Agency (No. 01-B07). N.K. is the grateful recipient of a fellowship from the Global COE Program, "Catalysis as the Basis for Innovation in Materials Science" from the Ministry of Education, Culture, Sports, Science and Technology (Japan).

\section{References and Notes}

(1) For recent reviews, see: (a) North, M. Synlett 1993, 807. (b) Effenberger, F. Angew. Chem. Int. Ed. Engl. 1994, 33, 1555. (c) Gregory, R. J. H. Chem. Rev. 1999, 99, 3649. (d) Enders, D.; Shilvock, J. P. Chem. Soc. Rev. 2000, 29, 359. (e) Yet, L. Angew. Chem. Int. Ed. 2001, 40, 875. (f) Shibasaki, M.; Kanai, M.; Funabashi, K. Chem. Commun. 2002, 1989. (g) North, M. Tetrahedron: Asymmetry 2003, 14, 147. (h) Gröger, H. Chem. Rev. 2003, 103, 2796. (i) Kanai, M.; Shibasaki, M. In Multimetallic Catalysts in Organic Synthesis; Shibasaki, M., Yamamoto, Y., Eds.; Wiley-VCH: Weinheim, 2004, 103. (j) Brunel, J.-M.; Holmes, I. P. Angew. Chem. Int. Ed. 2004, 43, 2752. (k) Kanai, M.; Kato, N.; Ichikawa, E.; Shibasaki, M. Synlett 2005, 1491. (1) Achard, T. R. J.; Clutterbuck, L. A.; North, M. Synlett 2005, 1828. (m) Chen, F.-X.; Feng, X. Curr. Org. Synth. 2006, 3, 77. (n) Taylor, M. S.; Jacobsen, E. N. Angew. Chem. Int. Ed. 2006, 45, 1520. (o) Shibasaki, M.; Kanai, M. Org.
Biomol. Chem. 2007, 5, 2027. (p) Shibasaki, M.; Kanai, M.; Mita, T. Org. React. 2008, 70, 1. (q) Khan, N. H.; Kureshy, R. I.; Abdi, S. H. R.; Agrawal, S.; Jasra, R. V. Coord. Chem. Rev. 2008, 252, 593. (r) North, M.; Usanov, D. L.; Young, C. Chem. Rev. 2008, 108, 5146. (s) Gawronski, J.; Wascinska, N.; Gajewy, J. Chem. Rev. 2008, 108, 5227. (t) Merino, P.; Marqués-López, E.; Tejero, T.; Herrera, R. P. Tetrahedron 2009, 65, 1219. (u) Wang, W.; Liu, X.; Lin, L.; Feng, X. Eur. J. Org. Chem. 2010, 4751. (v) Martens, J. Chem CatChem 2010, 2, 379. (w) Bergin, E. In Science of Synthesis: Stereoselective Synthesis, Vol. 2; Molander, G. A., Ed.; Thieme, Stuttgart, 2010, 531. (x) Wang, J.; Liu, X.; Feng, X. Chem. Rev. 2011, 111, 6947.

(2) See, for example: Poechlauer, P.; Skranc, W.; Wubbolts, M. In Asymmetric Catalysis on Industrial Scale: Challenge, Approaches and Solutions; Blaser, H. U., Schmidt, E., Eds.; Wiley-VCH, Weinheim, 2004, 151.

(3) (a) Evans, D. A.; Truesdale, L. K.; Carroll, G. L. J. Chem. Soc. Chem. Commun. 1973, 55. (b) Lidy, W.; Sundermeyer, W. Chem. Ber. 1973, 106, 587. (c) Noyori, R.; Murata, S.; Suzuki, M. Tetrahedron 1981, 37, 3899. (d) Greenlee, W. J.; Hangauer, D. G. Tetrahedron Lett. 1983, 24, 4559. (e) Vougioukas, A. E.; Kagan, H. B. Tetrahedron Lett. 1987, 28, 5513. (f) Reetz, M. T,; Drewes, M. W.; Harms, K.; Reif, W. Tetrahedron Lett. 1988, 29, 3295. (g) Faller, J. W.; Gundersen, L.-L. Tetrahedron Lett. 1993, 34, 2275. (h) Scholl, M.; Fu, G. C. J. Org. Chem. 1994, 59, 7178. (i) Cozzi, P. G.; Floriani, C. J. Chem. Soc. Perkin Trans. 1 1995, 2557. (j) Whitesell, J. K.; Apodaca, R. Tetrahedron Lett. 1996, 37, 2525. (k) Yang, Y.; Wang, D. Synlett 1997, 1379. (1) Komatsu, N.; Uda, M.; Suzuki, H.; Takahashi, T.; Domae, T.; Wada, M. Tetrahedron Lett. 1997, 38, 7215. (m) Loh, T.-P.; Xu, K.-C.; Ho. D. S.-C.; Sim, K.-Y. Synlett, 1998, 369. (n) Saravanan, P.; Anand, R. V.; Singh, V. K. Tetrahedron Lett. 1998, 39, 3823. (o) Bandini, M.; Cozzi, P. G.; Garelli, A.; Melchiorre, P.; Unami-Ronchi, A. Eur. J. Org. Chem. 2002, 3243. (p) King, J. B.; Gabbai, F. P. Organometallics 2003, 22, 1275. (q) Córdoba, R.; Plumet, J. Tetrahedron Lett. 2003, 44, 6157. (r) Baleizão, C.; Gigante, B.; Garcia, H.; Corma, A. Tetrahedron Lett. 2003, 44, 6813. (s) Karimi, B.; Ma'Mani, L. Org. Lett. 2004, 6, 4813.

(4) (a) Evans, D. A.; Truesdale, L. K. Tetrahedron Lett. 1973, 4929. (b) Ohta, H.; Hayakawa, S.; Moriwaki, H.; Harada, S.; Okamoto, M. Chem. Pharm. Bull. 1986, 34, 4916. (c) Kobayashi, S.; Tsuchida, Y.; Mukaiyama, T. Chem. Lett. 1991, 537. (d) Matsubara, S.; Takai, T.; Utimoto, K. Chem. Lett. 1991, 1447. (e) Ruble, J. C.; Fu, G. C. J. Org. Chem. 1996, 61, 7230. (f) Kantam, M. L.; Sreekanth, P.; Santhi, P. L. Green. Chem. 2000, 47. (g) Wilkinson, H. S.; Grover, P. T.; Vandedbossche, C. P.; Bakale, R. P.; Bhongle, N. N.; Wald, S. A.; Senanayake, C. H. Org. Lett. 2001, 3, 553. (h) Wang, Z.; Fetterly, B.; Verkade, J. G. J. Organomet. Chem. 2002, 646, 161. (i) Kim, S. S.; Rajagopal, G.; Song, D. G. J. Organomet. Chem. 2004, 689, 1734.

(5) No catalytic activity of $\mathrm{LiCl}$ with triglyme monomethyl ether in the reaction of camphor and TMSCN in THF was reported: see reference $4 \mathrm{~g}$.

(6) Kurono, N.; Yamaguchi, M.; Suzuki, K.; Ohkuma, T. J. Org. Chem. 2005, 70, 6530.

(7) Higuchi, K.; Onaka, M.; Izumi, Y. Bull. Chem. Soc. Jpn. 1993, 66, 2016.

(8) He, B.; Li, Y.; Feng, X.; Zhang, G. Synlett 2004, 1776.

(9) (a) Reetz, M.; T.; Fox, D. N. A. Tetrahedron Lett. 1993, 34, 1119. (b) Azizi, N.; Saidi, M. R. J. Organomet. Chem. 2003. 688, 283. 
(10) Kurono, N.; Suzuki, K.; Ohkuma, T. Lett. Org. Chem. 2006, 3, 275.

(11) (a) Foley, L. H. Synth. Commun. 1984, 14, 1291. (b) Vtazankina, O. A.; Gostevskii, B. A.; Vyazankin, N. S. J. Organomet. Chem. 1985, 292, 145. (c) Cohen, V. L.; Gibson, R. E.; Fan, L. H.; De La Cruz, R.; Gitler, M. S.; Hariman, E.; Reba, R. C. J. Med. Chem. 1991, 34, 2989. (d) Amurrio, I.; Córdova, R.; Csákÿ, A. G.; Plumet, J. Tetrahedron, 2004, 60, 10521.

(12) See, for example: Devant, R. M.; Radunz, H.-E. In Methods of Organic Chemistry (Houben-Weyl), Vol. E21b; Helmchen, G., Hoffmann, R. W., Mulzer, J., Schaumann, E., Eds.; Thieme: Stuttgart, 1995, 1151.

(13) The reaction of 2-benzyloxy-3-pentanone with $\mathrm{MeTi}[\mathrm{OCHMe}]_{3}$ was reported to afford a chelationcontrolled adduct exclusively, whereas the reaction of the $t$-butyldimethylsilyloxy analogue with the same reagent predominantly gave the non-chelationcontrolled product. See: Reetz, M. T.; Hüllmann, M. J. Chem. Soc. Chem. Commun. 1986, 1600.

(14) Holmes, I. P.; Kagan, H. B. Tetrahedron Lett. 2000, 41, 7457.

(15) Hatano, M.; Ikeno, T.; Miyamoto, T.; Ishihara, K. J. Am. Chem. Soc. 2005, 127, 10776.

(16) Ohkuma, T. Proc. Jpn. Acad., Ser. B 2010, 86, 202.

(17) (a) Arai, N.; Ooka, H.; Azuma, K.; Yabuuchi, T.; Kurono, N.; Inoue, T.; Ohkuma, T. Org. Lett. 2007, 9, 939. (b) Arai, N.; Azuma, K.; Nii, N.; Ohkuma, T. Angew. Chem. Int. Ed. 2008, 47, 7457. (c) Ooka, H.; Arai, N.; Azuma, K.; Kurono, N.; Ohkuma, T. J. Org. Chem. 2008, 73, 9084.

(18) Kurono, N.; Arai, K.; Uemura, M.; Ohkuma, T. Angew. Chem. Int. Ed. 2008, 47, 6643.

(19) $\mathrm{Ru}(\text { phenylalanyl })_{2}$ (binap) and $\mathrm{Ru}(\text { valinyl })_{2}$ (binap) were reported, see: Takaya, H.; Ohta, T.; Noyori, R.; Sayo, N.; Kumobayashi, H.; Akutagawa, S. EUR 0272787 A2, 1987; Chem. Abstr. 1989, 110, 114447.

(20) For selected leading studies on asymmetric cyanosilylation of aldehydes, see: (a) Reetz, M. T.; Kunisch, F.; Heitmann, P. Tetrahedron Lett. 1986, 27 , 4721. (b) Kobayashi, S.; Tsuchiya, Y.; Mukaiyama, T. Chem. Lett. 1991, 541. (c) Hayashi, M.; Miyamoto, Y.; Inoue, T.; Oguni, N. J. Org. Chem. 1993, 58, 1515. (d) Corey, E. J.; Wang, Z. Tetrahedron Lett. 1993, 34, 4001. (e) Hamashima, Y.; Sawada, D.; Kanai, M.; Shibasaki, M. J. Am. Chem. Soc. 1999, 121, 2641. (f) Belokon, Y. N.; Caveda-Cepas, S.; Green, B.; Ikonnikov, N. S.; Khrustalev, V. N.; Larichev, V. S.; Moscalenko, M. A.; North, M.; Orizu, C.; Tararov, V. I.; Tasinazzo, M.; Timofeeva, G. I.; Yashkina, L. V. J. Am. Chem. Soc. 1999, 121, 3968. (g) Belokon, Y. N.; North, M.; Parsons, T. Org. Lett. 2000, 2, 1617. (h) You, J.-S.; Gau, H.-M.; Choi, M. C. K. Chem. Commun. 2000, 1963. (i) Hamashima, Y.; Sawada, D.; Nogami, H.; Kanai, M.; Shibasaki, M. Tetrahedron 2001, 57, 805. (j) Chang, C.W.; Yang, C.-T.; Hwang, C.-D.; Uang, B.-J. Chem. Commun. 2002, 54. (k) Li, Y.; He, B.; Qin, B.; Feng, X.; Zhang, G. J. Org. Chem. 2004, 69, 7910. (1) Ryu, D. H.; Corey, E. J. J. Am. Chem. Soc. 2004, 126, 8106. (m) Qin, Y.-C.; Liu, L.; Pu, L. Org. Lett. 2005, 7, 2381. (n) Belokon, Y. N.; Maleev, V. I.; North, M.; Usanov, D. L. Chem. Commun. 2006, 4614. (o) Belokon, Y. N.; Clegg, W.; Harrington, R. W.; Young, C.; North, M. Tetrahedron 2007, 63, 5287. (p) Zhang, Z.; Wang, Z.; Zhang, B.; Ding, K. Angew. Chem. Int. Ed. 2010, 49, 6746.

(21) For cyanosilylation with $\mathrm{Li}_{2} \mathrm{CO}_{3}$ as a solid catalyst, see ref. 8 .
(22) For highly enantioselective cyanosilylation of primary alkyl aldehydes, see ref. 20d, e, 1, m.

(23) Recently, a chiral Ti-based catalyst with excellent reactivity was reported: see ref. $20 \mathrm{p}$.

(24) For reactions with Ti-based catalysts, see: (a) Belokon, Y. N.; Green, B.; Ikonnikov, N. S.; North, M.; Tararov, V. I. Tetrahedon Lett. 1999, 40, 8147. (b) Hamashima, Y.; Kanai, M.; Shibasaki, M. J. Am. Chem. Soc. 2000, 122, 7412. (c) Hamashima, Y.; Kanai, M.; Shibasaki, M. Tetrahedron Lett. 2001, 42, 691. (d) Belokon, Y. N.; Green, B.; Ikonnikov, N. S.; North, M.; Parsons, T.; Tararov, V. I. Tetrahedron 2001, 57, 771. (e) Shen, Y.; Feng, X.; Zhang, G.; Jiang, Y. Synlett 2002, 1353. (f) Chen, F.; Feng, X.; Qin, B.; Zhang, G.; Jiang, Y. Org. Lett. 2003, 5, 949. (g) Fujii, K.; Maki, K.; Kanai, M.; Shibasaki, M. Org. Lett. 2003, 5, 733. (h) Shen, Y.; Feng, X.; Li, Y.; Zhang, G.; Jiang, Y. Eur. J. Org. Chem. 2004, 129. (i) He, B.; Chen, F.-X.; Li, Y.; Feng, X.; Zhang, G. Eur. J. Org. Chem. 2004, 4657. (j) Xiong, Y.; Huang, X.; Gou, S.; Huang, J.; Wen, Y.; Feng, X. Adv. Synth. Catal. 2006, 348, 538. (k) Shen, K.; Liu, X.; Li, Q.; Feng, X. Tetrahedron 2008, 64, 147. (l) Yoshinaga, K.; Nagata, T. Adv. Synth. Catal. 2009, 351, 1495. See also ref. 11.

(25) For reactions with Gd- and Sm-based catalysts, see: (a) Yabu, K.; Masumoto, S.; Yamasaki, S.; Hamashima, Y.; Kanai, M.; Du, W.; Curran, D. P.; Shibasaki, M. J. Am. Chem. Soc. 2001, 123, 9908. (b) Yabu, K.; Masumoto, S.; Kanai, M.; Curran, D. P.; Shibasaki, M. Tetrahedron Lett. 2002, 43, 2923. (c) Masumoto, S.; Suzuki, M.; Kanai, M.; Shibasaki, M. Tetrahedron Lett. 2002, 43, 8647. (d) Yabu, K.; Masumoto, S.; Kanai, M.; Du, W.; Curran, D. P.; Shibasaki, M. Heterocycles 2003, 59, 369. (e) Masumoto, S.; Suzuki, M.; Kanai, M.; Shibasaki, M. Tetrahedron 2004, 60, 10497.

(26) For reactions with Al- and B-based catalysts, see: (a) Deng, H.; Isler, M. P.; Snapper, M. L.; Hoveyda, A. H. Angew. Chem. Int. Ed. 2002, 41, 1009. (b) Chen, F.-X.; Zhou, H.; Liu, X.; Qin, B.; Feng, X.; Zhang, G.; Jiang, Y. Chem. Eur. J. 2004, 10, 4790. (c) Ryu, D. H.; Corey, E. J. J. Am. Chem. Soc. 2005, 127, 5384. (d) Kim, S. S.; Kwak, J. M. Tetrahedron 2006, 62, 49. (e) Alaaeddine, A.; Roisnel, T.; Thomas, C. M.; Carpentier, J.-F. $A d v$. Synth. Catal. 2008, 350, 731. (f) Cao, J.-J.; Zhou, F.; Zhou, J. Angew. Chem. Int. Ed. 2010, 49, 4976. (g) North, M.; Omedes-Pujou, M.; Williamson, C. Chem. Eur. J. 2010, 16, 11367.

(27) For reactions with Na- and Li-based catalysts, see: (a) Liu, X.; Qin, B.; Zhou, X.; He, B.; Feng, X. J. Am. Chem. Soc. 2005, 127, 12224. (b) Hatano, M.; Ikeno, T.; Matsumura, T.; Torii, S.; Ishihara, K. Adv. Synth. Catal. 2008, 350, 1776.

(28) For reactions with organocatalysts, see: (a) Tian, S.-K.; Hong, R.; Deng, L. J. Am. Chem. Soc. 2003, 125, 9900. (b) Fuerst, D. E.; Jacobsen, E. N. J. Am. Chem. Soc. 2005, 127, 8964. (c) Qin, B.; Liu, X.; Shi, J.; Zheng, K.; Zhao, H.; Feng, X. J. Org. Chem. 2007, 72, 2374. (d) Zuend, S. J.; Jacobsen, E. N. J. Am. Chem. Soc. 2007, $129,15872$.

(29) For synthesis of chiral $\alpha$-cyano $\alpha$-silyloxy esters by a tandem cyanation-1,2-Brook rearrangement- $C$ acylation reaction of the acylsilanes, see: Nicewicz, D. A.; Yates, C. M.; Johnson, J. J. Org. Chem. 2004, 69, 6548.

(30) Kurono, N.; Uemura, M.; Ohkuma, T. Eur. J. Org. Chem. 2010, 1455.

(31) For achiral cyanosilylation of carbonyl compounds catalyzed by Li alkoxides, see ref. $4 \mathrm{~g}$.

(32) A Lewis base-catalyzed asymmetric acetylcyanation of $\alpha$-keto esters was reported. Methyl benzoylformate and 
tert-butyl 2-oxobutanoate were reacted with acetyl cyanide in the presence of cinchonidine $(\mathrm{S} / \mathrm{C}=10)$ at $78{ }^{\circ} \mathrm{C}$ to $-40{ }^{\circ} \mathrm{C}$ to afford the cyanated products in $66 \%$ and $82 \%$ ee, respectively. See: Li, F.; Widyan, K.; Wingstrand, E.; Moberg, C. Eur. J. Org. Chem. 2009, 3917.

(33) Mori, A.; Inoue, S. In Comprehensive Asymmetric Catalysis, Vol. 2; Jacobsen, E. N., Pfaltz, A., Yamamoto, H., Eds.; Springer: Berlin, 1999, 983.

(34) Herrmann, W. A. In Catalysis from A to Z: A Concise Encyclopedia; Cornils, B., Herrmann, W. A., Schlögl, R., Wong, C.-H., Eds.; Wiley-VCH: Weinheim, 2000, 533.

(35) Chemical Handbook (Kagaku Binran): Applied Chemistry (Oyo Kagaku Hen), Vol. 1; The Chemical Society of Japan, Ed.; Maruzen: Tokyo. 2003, 747.

(36) Reviews on enzymatic asymmetric synthesis of cyanohydrins: (a) Gröger, H. Adv. Synth. Catal. 2001, 343, 547. (b) Garcia-Urdiales, E.; Alfonso, I.; Gotor, V. Chem. Rev. 2005, 105, 313.

(37) For asymmetric synthesis catalyzed by oxynitrilases, see: (a) Griengl, H.; Schwab, H., Fechter, M. Trends Biotechnol. 2000, 18, 252. (b) Sharma, M.; Sharma, N. N.; Bhalla, T. C. Enzyme Microb. Technol. 2005. 37, 279.

(38) (a) Oku, J.; Inoue, S. J. Chem. Soc. Chem. Commun. 1981, 229. (b) Tanaka, K.; Mori, A.; Inoue, S. J. Org. Chem. 1990, 55, 181. See also: (c) Jackson, W. R.; Jayatilake, G. S.; Matthews, B. R.; Wilshire, C. Aust. J. Chem. 1988, 41, 203. (d) Danda, H. Synlett 1991, 263. (e) Danda, H.; Nishikawa, H.; Otaka, K. J. Org. Chem. 1991, 56, 6740 .

(39) For mechanistic studies, see: (a) North, M. Tetrahedron 1992, 48, 5509. (b) Shvo, Y.; Gal, M.; Becker, Y.; Elgavi, A. Tetrahedron: Asymmetry 1996, 7, 911. (c) Kogut, E. F.; Thoen, J. C.; Lipton, M. A. J. Org. Chem. 1998, 63, 4604. (d) Schoenebeck, F.; Houk, K. N. J. Org. Chem. 2009, 74, 1464.

(40) For asymmetric reactions catalyzed by synthetic peptides, see: Davie, E. A. C.; Mennen, S. M.; Xu, Y.; Miller, S. J. Chem. Rev. 2007, 107, 5759.

(41) (a) Abe, H.; Nitta, H.; Mori, A.; Inoue, S. Chem. Lett. 1992, 2443. (b) Nitta, H.; Yu, D.; Kudo, M.; Mori, A.; Inoue, S. J. Am. Chem. Soc. 1992, 114, 7969.

(42) Kurono, N.; Yoshikawa, T.; Yamasaki, M.; Ohkuma, T. Org. Lett. 2011, 13, 1254.

(43) Glemser, O. In Handbook of Preparative Inorganic Chemistry, 2nd ed.; Brauer, G., Riley, R. F., Eds.; Academic Press, New York, 1963, 658.

(44) For cyanation of $\alpha, \beta$-unsaturated ketones, see: (a) Tanaka, Y.; Kanai, M.; Shibasaki, M. J. Am. Chem. Soc. 2008, 130, 6072. (b) Tanaka, Y.; Kanai, M.; Shibasaki, M. J. Am. Chem. Soc. 2010, 132, 8862.

(45) For cyanation of $\alpha, \beta$-unsaturated imides, see: (a) Sammis, G. M.; Jacobsen, E. N. J. Am. Chem. Soc. 2003, 125, 4442. (b) Sammis, G. M.; Danjo, H.; Jacobsen, E. N. J. Am. Chem. Soc. 2004, 126, 9928. (c) Mazet, C.; Jacobsen, E. N. Angew. Chem. Int. Ed. Engl. 2008, 47, 1762. (d) Madhavan, N.; Weck, M. Adv. Synth. Catal. 2008, 350, 419.

(46) For cyanation of $\alpha, \beta$-unsaturated $N$-acylpyrroles, see: (a) Mita, T.; Sasaki, K.; Kanai, M.; Shibasaki, M. J. Am. Chem. Soc. 2005, 127, 514. (b) Fujimori, I.; Mita, T.; Maki, K.; Shiro, M.; Sato, A.; Furusho, S.; Kanai, M.; Shibasaki, M. Tetrahedron 2007, 63, 5820.

(47) For cyanation of other activated alkenes using acetone cyanohydrin or ethyl cyanoformate as a cyanide source, see: (a) Bernardi, L.; Fini, F.; Fochi, M.; Ricci, A. Synlett 2008, 1857. (b) Wang, J.; Li, W.; Liu, Y.; Chu, Y.; Lin, L.; Liu, X.; Feng, X. Org. Lett. 2010, 12, 1280.
(48) Kurono, N.; Nii, N.; Sakaguchi, Y.; Uemura, M.; Ohkuma, T. Angew. Chem. Int. Ed. 2011, 50, 5541.

(49) Use of isolated $\mathrm{HCN}$ as a cyanide source resulted in low yield and enantioselectivity in the reaction with the $\mathrm{Gd}$ catalyst. The $\mathrm{Sr}$ catalyst is expected to be labile with a large excess of HCN; for details see the ref. 44 .

(50) The conjugate cyanation of chalcone catalyzed by a chiral sodium phosphate with an $\mathrm{S} / \mathrm{C}$ of 5 afforded the $\beta$-cyano ketone in $71 \%$ ee. See: Yang, J.; Wu, S.; Chen, F.-X. Synlett 2010, 2725.

(51) For selected leading studies using organocatalysts, see: (a) Iyer, M. S.; Gigstad, K. M.; Namdev, N. D.; Lipton, M. J. Am. Chem. Soc. 1996, 118, 4910. (b) Sigman, M. S.; Jacobsen, E. N. J. Am. Chem. Soc. 1998, 120, 4901. (c) Corey, E. J.; Grogan, M. J. Org. Lett. 1999, 1, 157. (d) Sigman, M. S.; Vachal, P.; Jacobsen, E. N. Angew. Chem. Int. Ed. 2000, 39, 1279. (e) Vachal, P.; Jacobsen, E. N. J. Am. Chem. Soc. 2002, 124, 10012. (f) Jiao, Z.; Feng, X.; Liu, B.; Chen, F.; Zhang, G.; Jiang, Y. Eur. J. Org. Chem. 2003, 3818. (g) Huang, J.; Corey, E. J. Org. Lett. 2004, 6, 5027. (h) Ooi, T.; Uematsu, Y.; Maruoka, K. J. Am. Chem. Soc. 2006, 128, 2548. (i) Rueping, M.; Sugiono, E.; Azap, C. Angew. Chem. Int. Ed. 2006, 45, 2617. (j) Herrera, R. P.; Sgarzani, V.; Bernardi, L.; Fini, F.; Pettersen, D.; Ricci, A. J. Org. Chem. 2006, 71, 9869. (k) Pan, S. C.; Zhou, J.; List, B. Angew. Chem. Int. Ed. 2007, 46, 612. (1) Ooi, T.; Uematsu, Y.; Fujimoto, J.; Fukumoto, K.; Maruoka, K. Tetrahedron Lett. 2007, 48, 1337. (m) Wen, Y.; Xiong, Y.; Chang, L.; Huang, J.; Liu, X.; Feng, X. J. Org. Chem. 2007, 72, 7715. (n) Negru, M.; Schollmeyer, D.; Kunz, H. Angew. Chem. Int. Ed. 2007, 46, 9339. (o) Wen, Y.; Gao, B.; Fu, Y.; Dong, S.; Liu, X.; Feng, X. Chem. Eur. J. 2008, 14, 6789. (p) Zuend, S. J.; Coughlin, M. P.; Lalonds, M. P.; Jacobsen, E. N. Nature 2009, 461, 968. (q) Zamfir, A.; Tsogoeva, S. B. Org. Lett. 2010, 12, 188.

(52) For selected leading studies using metal-based catalysts, see: (a) Ishitani, H.; Komiyama, S.; Kobayashi, S. Angew. Chem. Int. Ed. 1998, 37, 3186. (b) Sigman, M. S.; Jacobsen, E. N. J. Am. Chem. Soc. 1998, 120, 5315. (c) Crueger, C. A.; Kuntz, K. W.; Dzierba, C. D.; Wirschun, W. G.; Gleason, J. D.; Snapper, M. L.; Hoveyda, A. H. J. Am. Chem. Soc. 1999, 121, 4284. (d) Ishitani, H.; Komiyama, S.; Hasegawa, Y.; Kobayashi, S J. Am. Chem. Soc. 2000, 122, 762. (e) Takamura, M.; Hamashima, Y.; Usuda, H.; Kanai, M.; Shibasaki, M. Angew. Chem. Int. Ed. 2000, 39, 1650. (f) Porter, J. R.; Wirschun, W. G.; Kuntz, K. W.; Snapper, M. L.; Hoveyda, A. H. J. Am. Chem. Soc. 2000, 122, 2657. (g) Keith, J. M.; Jacobsen, E. N. Org. Lett. 2004, 6, 153. (h) Banphavichit, V.; Mansawat, W.; Bhanthumnavin, W.; Vilaivan, T. Tetrahedron 2004, 60, 10559. (i) Blacker, J.; Clutterbuck, L. A.; Crampton, M. R.; Grosjean, C.; North, M. Tetrahedron: Asymmetry 2006, 17, 1449. (j) Wang, J.; Hu, X.; Jiang, J.; Dou, S.; Huang, X.; Liu, X.; Feng, X. Angew. Chem. Int. Ed. 2007, 46, 8468. (k) Nakamura, S.; Nakashima, H.; Sugimoto, H.; Sano, H.; Hattori, M.; Shibata, N.; Toru, T. Chem. Eur. J. 2008, 14, 2145. (1) Hatano, M.; Hattori, Y.; Furuya, Y.; Ishihara, K. Org. Lett. 2009, 11, 2321. (m) Banphavichit, V.; Mansawat, W.; Bhanthumnavin, W.; Vilaivan, T. Tetrahedron 2009, 65, 5849. (n) Wang, J.; Wang, W.; Li, W.; Hu, X.; Shen, K.; Tan, C.; Liu, X.; Feng, X. Chem. Eur. J. 2009, 15, 11642. (o) Abell, J. P.; Yamamoto, H. J. Am. Chem. Soc. 2009, 131, 15118. (p) Seayad, A. M.; Ramalingam, B.; Yoshinaga, K.; Nagata, T.; Chai, C. L. L. Org. Lett. 2010, 12, 264. (q) Kaur, P.; Pindi, S.; Wever, W.; Rajale, T.; Li, G. J. Org. Chem. 2010, 75, 
5144. (r) Karimi, B.; Maleki, A.; Elhamifar, D.; Clark, J. H.; Hunt, A. J. Chem. Commun. 2010, 46, 6947.

(53) (a) Petrini, M. Chem. Rev. 2005, 105, 3949. (b) Tillman, A. L.; Ye, J.; Dixon, D. J. Chem. Commun. 2006, 1191.

(54) Uemura, M.; Kurono, N.; Ohkuma, T. Org. Lett. 2012, 14,882 .

(55) The cyanation of an $\mathrm{N}$-arylsulfonyl primary alkyl imine at $0{ }^{\circ} \mathrm{C}$ catalyzed by a chiral quaternary ammonium salt with an S/C of 100 gave the nitrile product in $96 \%$ ee. See reference 511 for details.

(56) Nowick, J. M.; Lutterbach, G. In Encyclopedia of Reagents for Organic Synthesis, Vol. 5; Paquette, L. A., Ed.; Wiley: Chichester, 1995, 3063.

(57) (a) Dixon, D. A.; Hertler, W. R.; Chase, D. B.; Farnham, W. B.; Davidson, F. Inorg. Chem. 1988, 27, 4012. (b) Sassaman, M. B.; Prakash, G. K. S.; Olah, G. A. J. Org. Chem. 1990, 55, 2016.

(58) Hammett, L. P. Physical Organic Chemistry, $2^{\text {nd }}$ ed.; McGraw-Hill: New York, 1970, Chapter 11.

\section{Biographical Sketches}

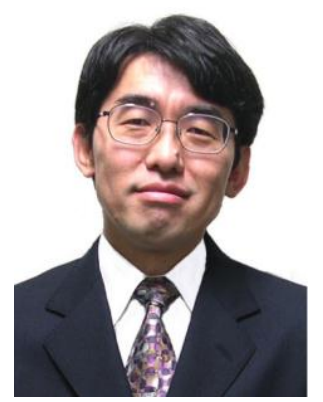

Takeshi Ohkuma received his $\mathrm{PhD}$ in 1991 from Nagoya University under the supervision of Professor Ryoji Noyori. After working with Professor Paul A. Wender at Stanford University, he joined the ERATO Noyori Molecular Catalysis Project in 1992. In 1996, he became an Associate Professor in the Department of Chemistry at Nagoya University, and was then promoted to Professor in the Division of Chemical Process Engineering at Hokkaido University in 2004. His research focuses on the development of novel catalytic reactions that achieve high levels of reactivity and selectivity. He received the Progress Award in Synthetic Organic Chemistry, Japan in 1997; the N. E. ChemCat Award in Synthetic Organic Chemistry, Japan in 1999; and the JSPS Prize (from Japan Society for the Promotion of Science) in 2007.

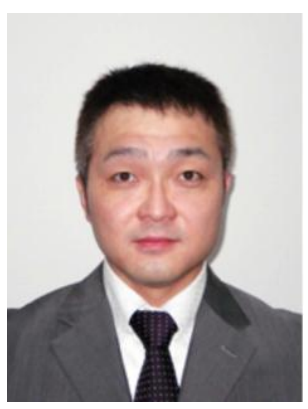

Nobuhito Kurono received his $\mathrm{PhD}$ in 2000 from Hokkaido University under the supervision of Professor Masao Tokuda. He then joined the Dissipative Hierarchy Structure Team, Frontier Research System, RIKEN (team leader: Professor Masatsugu Shimomura). In 2002, he became Assistant Professor in the Division of Chemical Process Engineering at Hokkaido University. His research focuses on the development of novel catalytic reactions and environmentally benign reactions. He received the Incentive Award in the Hokkaido Branch of Japan Chemical Society in 2011.

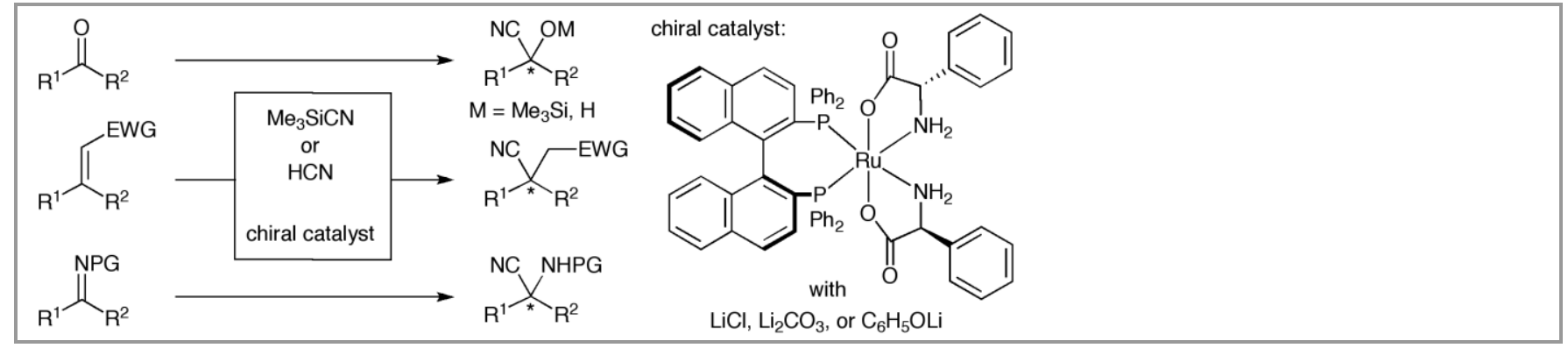

Graphical Abstract 